Document downloaded from:

http://hdl.handle.net/10251/149537

This paper must be cited as:

Desantes, J.; Bermúdez, V.; López, JJ.; López-Pintor, D. (2017). Sensitivity analysis and validation of a predictive procedure for high and low-temperature ignition delays under engine conditions for $n$-dodecane using a Rapid Compression-Expansion Machine. Energy Conversion and Management. 145:64-81. https://doi.org/10.1016/j.enconman.2017.04.092

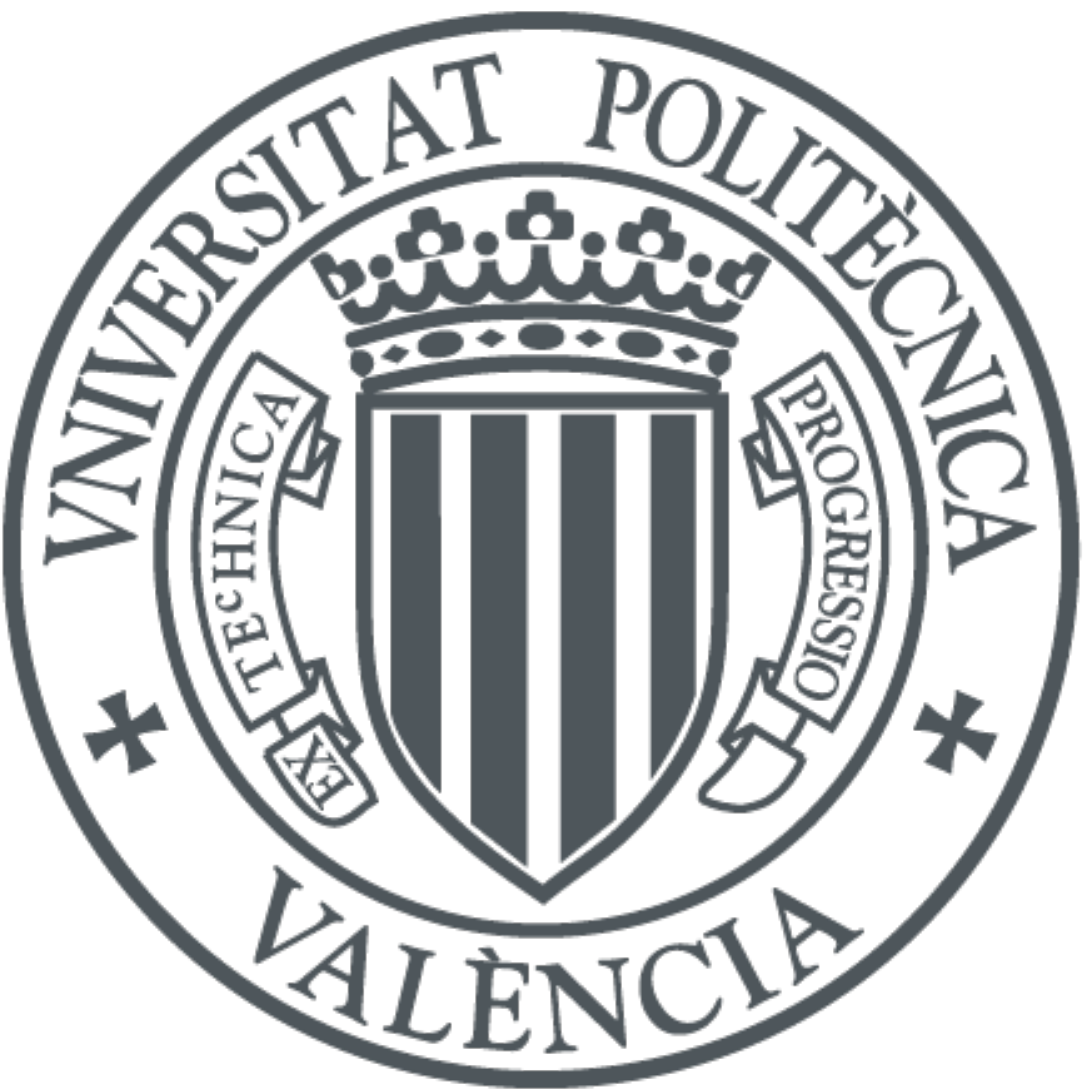

The final publication is available at

https://doi.org/10.1016/j.enconman.2017.04.092

Copyright Elsevier

Additional Information 


\title{
Sensitivity analysis and validation of a predictive procedure for high and low-temperature ignition delays under engine conditions for n-dodecane using a Rapid Compression-Expansion Machine
}

\author{
José M. Desantes ${ }^{\mathrm{a}}$, Vicente Bermúdez ${ }^{\mathrm{a}}$, J. Javier López ${ }^{\mathrm{a}, *}$, Darío \\ López-Pintor ${ }^{\mathrm{a}}$ \\ ${ }^{a}$ CMT-Motores Térmicos \\ Universitat Politècnica de València \\ Camino de Vera, s/n. 46022 Valencia, SPAIN
}

\begin{abstract}
A predictive procedure for cool flames and high-temperature ignition delays based on the accumulation and consumption of chain carriers has been validated for n-dodecane under engine conditions. To do so, an experimental parametric study has been carried out in a Rapid Compression-Expansion Machine, measuring the ignition times for different compression ratios (14 and 19), initial temperatures (from $403 \mathrm{~K}$ to $463 \mathrm{~K}$ ), $\mathrm{O}_{2}$ molar fractions (from 0.21 to 0.16 ) and equivalence ratios (from 0.4 to 0.7 ). The measured ignition delays have been compared to results from chemical kinetic simulations performed in CHEMKIN using a 0-D reactor that replicates the experimental conditions by solving five different chemical kinetic mechanisms, as a way to evaluate the mechanisms accuracy and variability. In general, all chemical kinetic mechanisms are able to accurately replicate the experimental ignition
\end{abstract}

\footnotetext{
*Corresponding author

Tel: +34 963879 232. Fax: +34963877 659. E-mail: jolosan3@mot.upv.es
} 
delays, being the mean relative deviation lower than $1.9 \%$ and $1.6 \%$ for both ignition stages, cool flames and the high-temperature ignition respectively. Furthermore, small differences have been appreciated between mechanisms in terms of ignition delay. Then, the predictive method has been applied using different databases obtained from each mechanism and a sensitivity analysis has been performed in order to evaluate the effects of the selected database on the predicted ignition delay. It has been found that while cool flames seems to be independent on the selected mechanism, the predicted high-temperature ignition delay is very sensitive to the species selected as chain carrier. Thus, if formaldehyde is assumed as ignition tracer, the predicted ignition time can vary up to $3 \%$, while this percent decreases up to $1.3 \%$ when hydrogen peroxide takes the role of chain carrier.

Keywords: RCEM, ignition delay, autoignition modeling, chemical kinetic mechanisms, CHEMKIN

\section{1. Introduction, justification and objective}

2 Combustion strategies based on the global autoignition of the in-cylinder 3 charge in internal combustion engines have become more relevant during the 4 last years due to their potential to reduce $\mathrm{NO}_{x}$ and soot emissions while keep5 ing or even increasing the engine efficiency. New compression ignition (CI) 6 engines based on the autoignition of a reactive mixture, such as the Homoge7 neous Charge Compression Ignition (HCCI) engine, the Reactive Controlled 8 Compression Ignition (RCCI) engine and others, have been widely studied 9 concluding that both the soot and $\mathrm{NO}_{x}$ formation peninsulas, which can be seen in equivalence ratio - temperature diagrams [1], can be avoided by com- 
bining massive Exhaust Gas Recirculation (EGR) rates and lean equivalence ratios, leading to Low Temperature Combustion (LTC) regimes.

On the one hand, LTC regimes have shown to be a good method to improve combustion stability, $\mathrm{NO}_{x}$ emissions and fuel consumption with respect to conventional Spark Ignition (SI) engines [2]. Quenching effects near the walls are less relevant when an autoignition occurs, resulting in a higher combustion efficiency, while the maximum local in-cylinder temperature reached in the cycle is also reduced due to the absence of a flame front, resulting in a lower $\mathrm{NO}_{x}$ generation by the thermal way. Finally, since in autoignition modes the start of combustion does not depend on the local conditions near the spark plug, lower cycle-to-cycle dispersion is usually obtained under affordable engine loads [3].

On the other hand, LTC regimes have shown to be a good solution for the well-known trade-off between soot and $\mathrm{NO}_{x}$ in conventional diesel engines, in which strategies to reduce soot cause an increase of $\mathrm{NO}_{x}$ emissions and vice versa [4]. Soot formation can be avoided by working with lean equivalence ratios while $\mathrm{NO}_{x}$ generation can be highly reduced by decreasing the combustion temperature [5]. Thus, the autoignition of lean mixtures with low oxygen content leads to a combustion almost free of soot and $\mathrm{NO}_{x}$. However, LTC regimes are characterized by higher emissions of Unburned Hydrocarbons (UHC) and Carbon Monoxide (CO) compared to the conventional diesel combustion, but such emissions can be easily eliminated under typical operating conditions with well-known after-treatment techniques to fulfill the standard limits.

Investigations have shown two main challenges to overcome for the im- 
plementation of LTC modes in commercial engines. First, these combustion strategies are characterized by low Damkhöler numbers, which implies that the ignition is controlled by chemical kinetics [6]. The reactivity of the mixture can be modified by adjusting the engine operating parameters, but the absence of an explicit controlling event causes a more complex phasing of the heat release rate. Secondly, too high pressure rise rates can be reached when the engine load is increased because of the high combustion velocities reached in autoignition events, which leads to high combustion noise and mechanical stresses [7]. The load range at which the engine is able to work depends on the fuel autoignition tendency. Thus, low octane number fuels are required for low and medium loads, while high octane number fuels are required for high engine loads [8].

These challenges require to improve the capability of predicting the autoignition event in order to properly modify the operating conditions of the engine and, by this way, controlling the heat release. Moreover, such predictive capabilities should be validated not only for standard gasoline or diesel fuels, but for a wide range of octane numbers in order to cover a wide range of engine loads.

Numerical calculations to obtain the ignition delay under engine conditions can be divided in two main groups: chemical kinetic mechanisms and phenomenological predictive methods. On the one hand, detailed chemistry is able to replicate reasonably well the fuel oxidation phenomenon. However, thousand of reactions are needed to properly describe the process and, therefore, the implementation of such methods in CFD simulations or in an engine control unit (ECU) is highly limited by the computation time. On 
the other hand, phenomenological predictive methods can be easily linked to CFD codes to determine the ignition event, but loosing all the information related to the species evolution. Hu et al. [9], for instance, used the Livengood \& Wu integral method as a reaction progress variable to determine the instant and place of ignition for heterogeneous mixtures in CFD calculatuions. Moreover, due to their low computational cost, phenomenological predictive methods can be implemented in an ECU that can obtain information on the ignition delay in real time. Thus, the engine operating conditions can be modified according to the ignition delay predictions, controlling the heat release. However, the main predictive method existing nowadays is the classic Livengood \& Wu correlation [10] and only few alternatives can be found in the literature, most of them based on the Livengood \& Wu method itself.

The Livengood \& Wu integral method allows to obtain ignition delays of processes under transient conditions of temperature and pressure by using the ignition characteristics under constant thermodynamic conditions, which are much easier to obtain both experimentally and by simulation. The expression proposed by these authors is the following:

$$
\int_{0}^{t_{i}} \frac{1}{\tau} d t=1
$$

where $t_{i}$ is the ignition delay of the process and $\tau$ is the ignition delay under constant conditions of pressure and temperature for the successive thermodynamic states.

Despite the fact that this method was enunciated for knock prediction in SI-engines [11], it has been extended to CI-engines as a way to control the 
ignition by predicting the ignition delay of homogeneous air-fuel mixtures as the ones used in LTC modes [12]. In fact, the implementation of the Livengood \& Wu integral method in an ECU has been studied by several authors. Choi et al. [13] trained an artificial neural network to predict ignition delays under constant thermodynamic conditions, $\tau$, by means of the data obtained in a perfectly stirred reactor solving a detailed mechanism. The artificial neural network was linked to the Livengood \& Wu integral method to predict ignition delays under HCCI conditions. The computing time was short enough to use this method for real-time dynamic control of HCCI engine combustion. Rausen et al. [14] proposed a mean-value model to control HCCI engines, in which the start of combustion is given by the Livengood \& Wu integral method. Empirical correlations was used to parameterize the ignition delay under constant conditions, while the model was validated using steady-state test data from an experimental gasoline engine. Ohyama [15] integrated different physical models of intake (including EGR effects), combustion and thermodynamics for the engine control. Limits of the in-cylinder air/fuel ratio to avoid misfire or knocking were obtained by simulation, using the Livengood \& Wu integral as the autoignition model. Besides, Hillion et al. [16] proposed an open-loop control strategy to improve the stability during transients of a conventional CI Diesel engine. The Livengood \& Wu integral method was used to adjust the injection time and avoid too violent ignitions. This strategy was implemented in a real engine, which was tested on a test bench and on-board a vehicle, and showed promising results in terms of combustion stability, pollutant emissions and noise. Finally, Zhou et al. [17] proposed mathematical correlations for the ignition delay 
under constant conditions, $\tau$, based on simulations solving detailed chemical kinetic mechanisms for different fuels. The authors used these correlations to solve the Livengood \& $\mathrm{Wu}$ integral method and predict the ignition under engine conditions. The comparison of predictions to 0-D simulations with detailed chemistry showed that the Livengood \& Wu integral method is able to accurately reproduce the ignition characteristics at an insignificant computational cost, leading to method to control the ignition in real time. Similar correlations have been proposed by DelVescovo et al. [18] for PRF mixtures. The authors tested their correlations using the Livengood \& Wu integral method and comparing the predictions to experimental HCCI heavy-duty engine data, obtaining a mean deviation of 1.5 CAD between predictions and experimental results.

The Livengood \& Wu correlation has been recently used as an autoignition model for alternative fuels. Amador et al. [19], for instance, used the integral method to predict knock in an internal combustion engine fueled with Syngas. Their results showed that knock appears earlier if the methane number of the fuel increases. Besides, Kalghatgi et al. [20] tested the Livengood \& Wu integral with five fuels that have different octane number values, sensitivities, and compositions, including ethanol blends. Predictions were compared to experiments in a single cylinder engine over a wide range of operating conditions, confirming that knock can be accurately predicted.

However, Yates et al. [21] showed that the validity of the Livengood \& Wu integral is compromised when a two-stage ignition occurs, since this method describes the autoignition process by a global zero order reaction that is not able to describe the NTC behavior. In fact, the hypotheses and limits of 
application of the integral method have been studied by Desantes et al. [22], concluding that only cool flames can be properly predicted during the NTC zone, but not the high-temperature ignition delay. Furthermore, the need to develop simple numerical methods to predict both ignition stages has been shown by several authors. Liang and Reitz [23] claimed that one-step reaction to approximate the autoignition mechanism, as in the Livengood \& $\mathrm{Wu}$ integral, seems to be not enough to properly reproduce the phenomenon of knocking in SI engines. In fact, these authors proposed the use of detailed chemical kinetic mechanisms to predict the ignition delay. However, this methodology leads to very long computing times. Besides, Edenhofer et al. [24] generated a database of ignition characteristics of diesel fuel under atmospheric pressure, proposing the use of such database in autoignition models to predict the ignition delay under transient conditions. Edenhofer et al. took into account five different results in their measurements: no ignition, unstable cool flames, cool flames, slow oxidation and thermal explosion; which leads to different ignition events. However, few predictive methods that distinguish the different stages present in a two stage ignition pattern are available.

Hernandez et al. [25] analyzed the validity of the Livengood \& Wu integral by solving different chemical kinetic mechanisms for several fuels, concluding that the predictive capability loses its accuracy if a two stage ignition pattern occurs. Besides, the authors also proposed two alternative procedures with the aim of being able to predict the high-temperature ignition stage during the NTC zone. One of the two methods proposed showed worse results than the Livengood \& Wu integral, while the other alternative had better accuracy despite of being based on the same hypotheses. 
Moreover, Pan et al. [26] modified the original Livengood \& Wu correlation to extend its validity to fuels that show a two stage ignition pattern. The integral method was solved in two stages. On the one hand, the integral was solved using the ignition characteristics of cool flames, which result in the cool flames prediction. On the other hand, the integral was solved from the cool flames instant using the NTC parameterization, which results in the high-temperature prediction. The method showed satisfactory predictive capability when the temperature increment associated to cool flames was taken into account.

Desantes et al. [27, 28] have proposed different phenomenological procedures based on the Glassman's model [29] to predict ignition delays referred to a critical concentration of chain carriers. However, only ignition delays referred to critical concentrations can be accurately predicted because all these methods define the ignition as the instant at which a critical concentration of chain carriers is reached. Therefore, ignition delays referred to the high exothermic stage of the process cannot be calculated, since the critical concentration is reached in a previous stage. Desantes et al. [30] have also proposed an alternative method to predict both high-temperature stage and cool flames ignition delays under transient thermodynamic conditions, which has been validated for a wide range of octane numbers (from 0 to 100 at steps of 25) [31]. This predictive procedure calculates the ignition delay under transient conditions by means of the ignition delay, $\tau$, and critical concentration, $[C C]_{\text {crit }}$, data under constant conditions of temperature and pressure, which can be easily parameterized. Moreover, the needed database can be obtained by solving a chemical kinetic mechanism in a close 0 -D per- 
fectly stirred reactor. Therefore, the predictive method seems to be sensitive to the species that takes the role of chain carrier and to the mechanism solved to determine $\tau$ and $[C C]_{\text {crit }}$.

In the present paper, a sensitivity analysis of the predictive method proposed by Desantes et al. [30] has been performed in order to know the dependence of the results to the chemical kinetic mechanisms used and to the species selected as chain carrier. The study has been done with n-dodecane in order to extend the validity of the predictive procedure to fuels that are more prone to autoignite than n-heptane, which has an octane number equal to 0 . Besides, investigations with n-dodecane are interesting due to the absence of experimental measurements of the ignition characteristics of this fuel under engine conditions in the literature, so that the experimental ignition delay trends should be analyzed. Simulations have been performed with CHEMKIN by solving five different chemical kinetic mechanisms. Thus, five different databases have been tested in the predictive procedure. Finally, the numerical results have been validated experimentally using a Rapid Compression-Expansion Machine (RCEM).

The structure of the paper is the following: first, the experimental facility is presented. Secondly, the methodological approach is described, including the experimental methods, the predictive procedure, the chemical kinetic simulations and the parametric study performed. Afterwards, the experimental ignition delay trends are analyzed. Then the chemical kinetic mechanisms are validated by comparison to the experimental results and their variability is analyzed. Afterwards, the predictive capability of the method is compared with the accuracy of the chemical kinetic simulations, and the 
sensitivity to use different databases is analyzed. Finally, the conclusions of this study are shown.

\section{Materials and methods}

The sensitivity of the predictive procedure to the used database was analyzed by comparison with the variability of different chemical kinetic mechanisms following this methodology: for a certain case, the ignition delay was obtained experimentally and by simulation solving five different chemical kinetic mechanisms, analyzing the mechanisms accuracy and variability. Then, the evolution of both the in-cylinder temperature and pressure were experimentally obtained under motoring conditions. The ignition delay, $\tau$, and the critical concentration, $[C C]_{\text {crit }}$, were obtained for each thermodynamic state by simulation in a perfectly stirred reactor using each of the tested mechanisms, leading to five different databases. Finally, the ignition delay under transient conditions was then predicted with the phenomenological method indicated before ([30], a summary of which will be presented in Section 2.2) by using each database, and the predictive capability and variability of the method were compared to the corresponding in the simulated results.

\subsection{Rapid Compression Expansion Machine}

An RCEM is an experimental facility in which both compression and expansion strokes of an internal combustion engine can be replicated under fully controlled initial and boundary conditions, while avoiding the complexities and uncertainties related to engines [32].

The main characteristics of the RCEM used in this investigation can be seen in Table 1. Different compression ratios can be reached by varying 
the stroke or the clearance volume, i.e., varying the position of Top Dead Center (TDC), while the compression velocity can also be varied in order to reproduce different engine speeds. Details on the operation principle of the RCEM can be found in [28].

\begin{tabular}{|l|ll|}
\hline Bore & 84 & $\mathrm{~mm}$ \\
\hline Stroke & $120-249$ & $\mathrm{~mm}$ \\
\hline Compression ratio & $5-30$ & - \\
\hline Maximum cylinder pressure & 200 & $\mathrm{bar}$ \\
\hline Initial pressure & $1-5$ & $\mathrm{bar}$ \\
\hline Maximum heating temperature & 473 & $\mathrm{~K}$ \\
\hline
\end{tabular}

Table 1: Technical characteristics of the RCEM.

The pushing piston and the driver piston are instrumented with two AMO LMK102 incremental position sensors (0.01 $\mathrm{mm}$ of resolution), which allow knowing the absolute position of each piston and, therefore, the combustion chamber volume. Besides, the experimentation piston consists of a steelmade piston with a $84 \mathrm{~mm}$ bore and a quartz-made bowl with cylindrical shape, $46 \mathrm{~mm}$ of bore and $17 \mathrm{~mm}$ in depth, which allows the axial optical access.

The wall temperature is measured by three thermocouples located in the liner, in the piston and in the bowl. The temperature of the bowl can be varied by a ring-shape electrical $80 \mathrm{~W}$ heater, while the temperature of the cylinder walls is modified by two more spire-shape electrical heaters of $600 \mathrm{~W}$ each located in the liner. The intake and exhaust ducts, which are located in the liner, are designed to induce swirl motion to the gases admitted by 
the RCEM during the filling procedure, resulting in a homogeneous initial temperature in the chamber equal to the wall temperature (as demonstrated by some previous CFD calculations [33]).

The cylinder head is instrumented with a Kistler 6045A uncooled piezoelectric pressure sensor with a sensitivity of $-45 p C /$ bar, coupled to a Kistler 5018 charge amplifier, and whereby the in-cylinder pressure is measured. Three Wika piezoresistive pressure sensors are avaliable to control the filling of the driving gas and of the combustion chamber with a resolution of 0.01 bar. The injection system is a conventional common rail system that includes a $\mathrm{BOSCH}$ solenoid-commanded injector with a 7-hole nozzle and that is controlled by an EFS IPod power driving module. This injection system has been characterized as explained in [34]. The acquisition system is a Yokogawa DL850V composed by one $10 \mathrm{MHz}-12$ bits module and five more $1 M H z-16$ bits modules with two channels each. The acquisition frequency is fixed to $10 \mathrm{M} \mathrm{Hz}$, which is necessary to capture the pulses of the incremental position sensor. However, the in-cylinder pressure and the injection pressure are recorded at $1 \mathrm{MHz}$.

The synthetic mixture from which the RCEM is filled is generated in an external tank by a filling based on partial pressures where $\mathrm{N}_{2}, \mathrm{CO}_{2}$ and $\mathrm{O}_{2}$ are available. Besides, $\mathrm{H}_{2} \mathrm{O}$ can be added by means of a syringe pump and the fuel can be delivered into the tank by means of the same injection system than the one used in the RCEM (previously described). Thus, the tank can be heated up to $520 \mathrm{~K}$ by three electrical heaters of $1200 \mathrm{~W}$ each to ensure both $\mathrm{H}_{2} \mathrm{O}$ and fuel vaporization. A vacuum pump is used to ensure the no contamination of the mixture composition in this tank, nor in the RCEM 
charge. Finally, the synthetic air is analyzed by gas chromathography in a Rapid Refinery Gas Analyser from Bruker (450-GC) in order to know the exact composition and ensure the correct reproduction of the experiments in CHEMKIN.

The composition of the synthetic gas mixture used in this study was considered as the products of a complete combustion reaction between the fuel and dry air in which the amount of oxygen is the one desired by the user, as explained in [35]. Vacuum is created in the combustion chamber before the filling, and the fuel is injected directly into the combustion chamber at the start of the intake process to avoid problems of stratification or other inhomogeneities. The turbulence generated during the filling, as well as the long duration of the process $(\approx 40 s)$, are enough to guarantee a homogeneous environment in the chamber when the compression stroke starts.

The temperature profile is calculated for each experiment by applying the equation of state, since the pressure profile and the piston position are known, while the heat release rate (HRR) is obtained by means of the energy equation. The heat losses are characterized by a model based on the Woschni correlation [36], and two additional models for deformations and leaks, both of them explained in $[37,38]$, are included in the calculations.

In order to ensure a representative ignition delay time measurement, the number of repetitions of each point has been selected so that the semiamplitude of the confidence interval with a level of confidence of $95 \%$ is smaller than $1 \%$ of the mean ignition delay value. Besides, a minimum of 5 repetitions are performed for each operating condition.

Two different criteria have been assumed to define the start of ignition: 


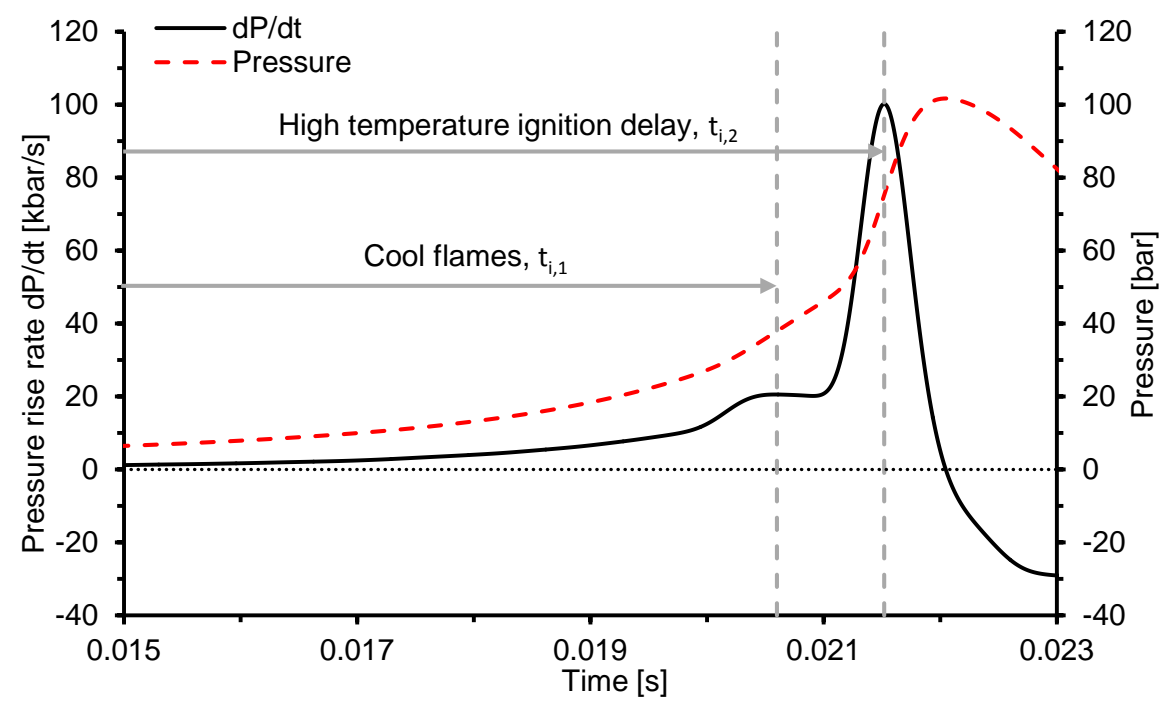

Figure 1: Ignition delay definition based on the pressure rise rate. The autoignition of the mixture is considered to be produced when a maximum pressure rise rate occurs.

in one case it is to be consistent with the predictive procedure evaluated in this investigaciton, whereas in the otehr case is to avoid intrinsic deviations in this parameter when the experimental one is compared with the one simulated by CHEMKIN, because of the absence of wall effects in the latter case. Both criteria have been applied to the experimental results, the coherence and consistence of which have been checked by comparing the ignition delay trends (Appendix C). On the one hand, the ignition time is defined as the instant at which the pressure rise rate reaches a maximum, which allows to distinguish both cool flames and the high-temperature stage of the process if a two-stage ignition pattern occurs. Fig. 1 shows an example of this criterion, in which the ignition delay $\left(t_{i, 1-\max }\right.$ or $t_{i, 2-\max }$ for cool flames and high-temperature, respectively) is defined as the time between the start of the 


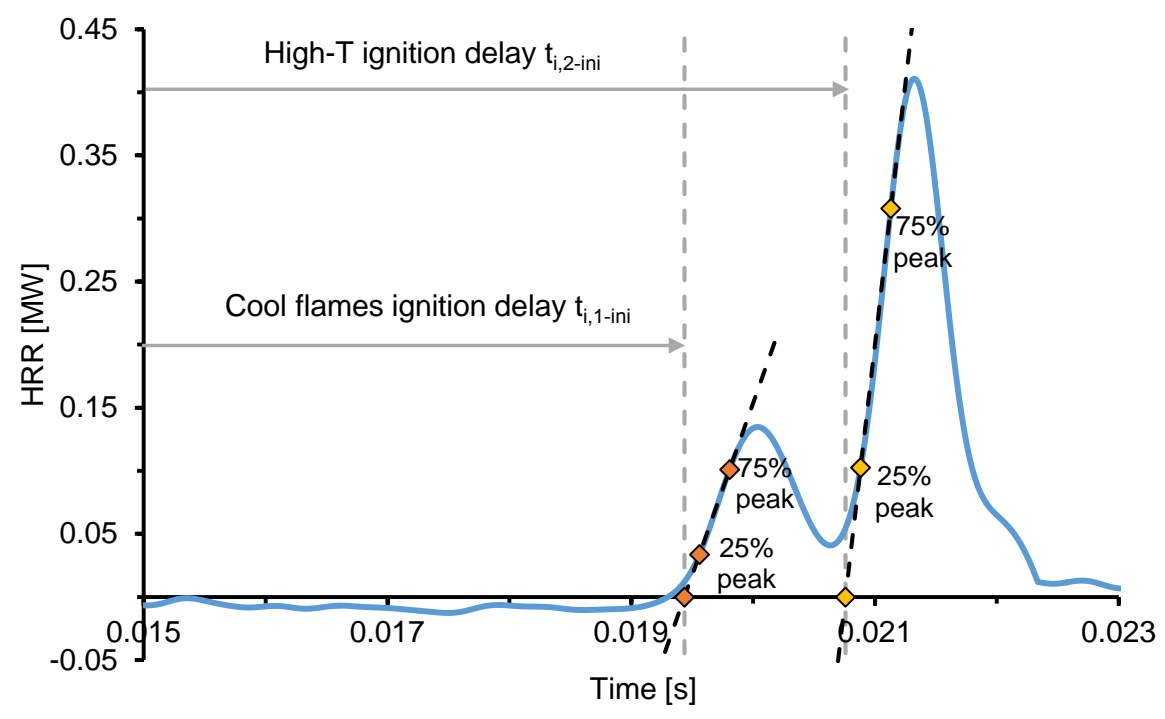

Figure 2: Ignition delay definition based on the heat release rate. The autoignition of the mixture is considered to be produced when the crossing through zero of a secant line of the HRR occurs. The presented case is the same as the one already shown in Fig. 1.

rapid compression stroke (which is a constant reference due to constructive aspects of the machine) and the calculated (from the maximum pressure rise rate) ignition time. This ignition delay definition is mandatory to compare the results from the predictive procedure proposed by Desantes et al. [30] to the experimental data, as it will be demonstrated in Section 2.2.

On the other hand, the autoignition of the mixture is considered to be produced when the first signs of combustion are visible. The location of the combustion initiation can be seen more easily in the HRR profile, rather than in the pressure rise rate. More specifically, ignition is defined as the crossing through zero of a secant line of the HRR as described in Fig. 2. As it can be seen, both cool flames and the high-temperature stage of the 
process can be identified when a two-stage ignition pattern occurs. The points at $75 \%$ and $25 \%$ of the maximum HRR referred to each ignition stage are selected for the calculation of the secant line and the subsequent ignition time. $25 \%$ of the maximum HRR has been selected in order to avoid wrong calculations of the secant line when cool flames and the high-temperature stage are coupled. Besides, $75 \%$ of the maximum HRR has been selected in order to avoid undesirable effects of the rounded peak of the HRR on the slope of the secant line. Thus, the ignition delay $\left(t_{i, 1-i n i}\right.$ or $t_{i, 2-i n i}$ for cool flames and high-temperature, respectively) in the experimental facility is defined as the time between the start of the rapid compression process and the calculated (from the start of the HRR) ignition time.

\subsection{Alternative predictive method for ignition delays}

The predictive procedure to obtain high and low-temperature ignition delays under transient thermodynamic conditions proposed by Desantes et al. [30] is based on the accumulation and consumption of chain carriers, relating the evolution of the chain carriers concentration to cool flames and to the high-exothermic stage of the process.

The accumulation and consumption of chain carriers are modelled by the predictive procedure proposed by Desantes et al. [30] by the following two consecutive integrals:

$$
\begin{aligned}
& 1=\frac{1}{[C C]_{\max , t_{i, C C}}} \int_{0}^{t_{i, C C}} \frac{[C C]_{\max }}{\tau_{C C}} d t \\
& 1=\frac{1}{[C C]_{\max , t_{i, C C}}} \int_{t_{i, C C}}^{t_{i, 2-\max }} \frac{[C C]_{\max }}{\tau_{2}-\tau_{C C}} d t
\end{aligned}
$$


where $t_{i, C C}$ is the ignition delay of the process referred to a maximum concentration of chain carriers and $t_{i, 2-\max }$ is the ignition delay referred to the maximum pressure rise rate caused by the high-temperature stage of combustion. Besides, $\tau_{2}, \tau_{C C}$ and $[C C]_{\max }$ are the ignition delay referred to the high exothermic stage, the ignition delay referred to a maximum of chain carriers and the critical concentration of chain carriers, respectively, under constant conditions of pressure and temperature for the successive thermodynamic states. Cool flames can be predicted by modeling the accumulation behavior of the hydroperoxyl radical $\left(\mathrm{HO}_{2}\right)$, while the high-exothermic stage can be predicted by modeling first the accumulation and then the consumption of hydrogen peroxide $\left(\mathrm{H}_{2} \mathrm{O}_{2}\right)$ or formaldehyde $\left(\mathrm{CH}_{2} \mathrm{O}\right)$, indistinctly.

A schematic of the procedure can be seen in Appendix A. Finally, a detailed description about the theoretical development that defines this predictive procedure can be found in [28] and [30], while a validation of the method for pure iso-octane and pure n-heptane, and for PRF25, PRF50 and PRF75 can be found in [30] and [31], respectively. The results obtained from the predictive procedure will be named as predictions further on.

\subsection{CHEMKIN and chemical kinetic mechanisms}

CHEMKIN-PRO is the software used for the simulations, which covers not only the modeling of the autoignition process that takes place in the RCEM, but also the generation of the database needed to solve the integrals that form the predictive procedure evaluated in this investigation. Five different chemical kinetic mechanisms have been evaluated in order to analyze the variability of the predictive method when the database of ignition delays and critical concentrations changes, all of them summarized in Table 2. 


\begin{tabular}{|l|c|c|c|}
\hline \multicolumn{1}{|c|}{ Mechanism } & Species & Reactions & Ref. \\
\hline LLNL reduced & 163 & 887 & {$[39]$} \\
\hline Narayanaswamy & 225 & 1509 & {$[40]$} \\
\hline Luo & 105 & 420 & {$[41]$} \\
\hline Wang & 100 & 432 & {$[42]$} \\
\hline Yao & 54 & 269 & {$[43]$} \\
\hline
\end{tabular}

Table 2: Chemical kinetic mechanisms evaluated.

Fig. 3 shows that higher combustion pressures and pressure rise rates are obtained in the simulations. This is due to the absence of wall effects in the 0-D model. Thus, the combustion development is slower in the experimental facility due to the existence of a temperature gradient near the walls, which implies the existence of a cold gas volume that leads to a progressive ignition event. However, this result does not invalidate the analysis on the ignition delay. If a homogeneous gas bulk is generated in the combustion chamber, the in-cylinder conditions referred to such gas core can be replicated in the 0-D model before the ignition, leading to a proper evaluation of the chemical kinetics referred to the ignition delay. Finally, the existence of such homogeneous gas bluk has been demonstrated in [33].

Furthermore, it can be seen in Fig. 3 that a definition of the ignition delay based on the pressure rise rate leads to intrinsic deviations between experiments and simulations because of the absence of wall effects in the 0-D model. I.e., in case of having the start of ignition at the same instant in both experiments and simulations, the maximum pressure rise rate will occur later in the experiments because of the slower combustion propagation, leading to 


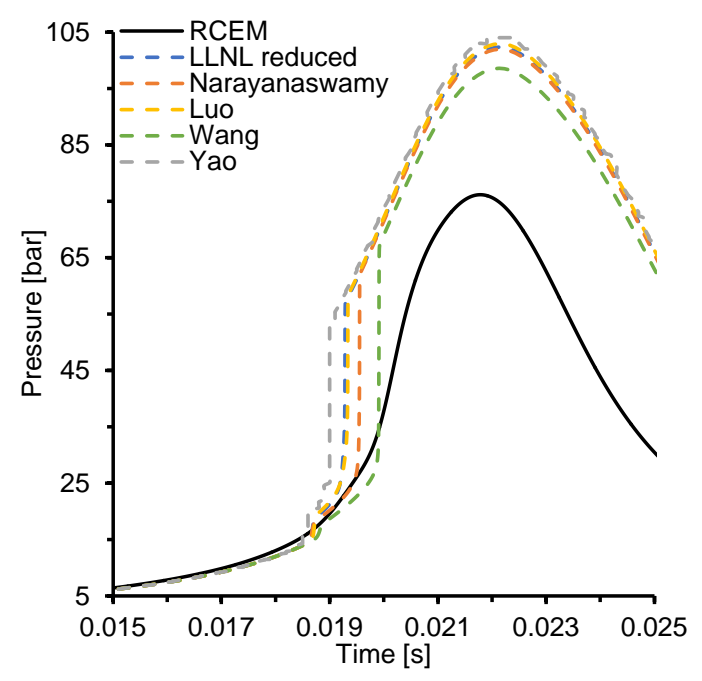

Figure 3: In-cylinder pressure trace obtained experimentally and by simulation for $\mathrm{X}_{\mathrm{O}_{2}}$ $=0.21, \mathrm{CR}=19, \mathrm{~T}_{i}=463 \mathrm{~K}$ and $\mathrm{Fr}=0.6$. Results form all the tested chemical kinetic mechanisms are plotted.

a certain deviation that is not caused by the chemical kinetic mechanisms. This is the reason why an alternative ignition delay definition based on the determination of the combustion onset (already presented in Section 2.1) has been used in this investigation. The crossing through zero of the secant line that passes through the $75 \%$ and the $25 \%$ of the maximum HRR defines the ignition onset, and at this point the differences between experimental and modeling data caused by wall effects are not relevant. Therefore, the criterion to define the ignition should be carefully selected, since additional deviations caused by the ignition delay definition can be present because of the absence of wall effects in the CHEMKIN 0-D simulations.

Thus, different ignition delays are defined from the simulations, since different definitions are needed to properly compare the results to experimental 
data or to apply these data in the predictive method:

- $\tau_{1}$ is the ignition delay under constant thermodynamic conditions referred to the maximum pressure rise rate caused by cool flames.

- $\tau_{2}$ is the ignition delay under constant thermodynamic conditions referred to the maximum pressure rise rate caused by the high-temperature stage of the combustion process.

- $\tau_{C C}$ is the ignition delay under constant thermodynamic conditions referred to the critical concentration of chain carriers. Different species are proposed as chain carrier depending on the stage of the ignition to be predicted: $C C=\mathrm{HO}_{2}$ has been tested for cool flames, while $C C=\mathrm{CH}_{2} \mathrm{O}$ and $C C=\mathrm{H}_{2} \mathrm{O}_{2}$ have been tested for the high-temperature stage of the process.

$\tau_{1}$ and $\tau_{2}$ are referred to a peak of the pressure rise rate signal, since they compose the database that will be used in the predictive procedure and, therefore, they have to be referred to a maximum $d P / d t$ in order to be consistent with the predictive method.

The ignition delays under transient thermodynamic conditions obtained from simulations are the following:

- $t_{i, 1-i n i}$ is the ignition delay under transient thermodynamic conditions referred to the crossing through zero of the secant line that passes through the $75 \%$ and the $25 \%$ of the maximum HRR caused by cool flames. This ignition delay is also experimentally obtained.

- $t_{i, 2-i n i}$ is the ignition delay under transient thermodynamic conditions referred to the crossing through zero of the secant line that passes 
through the $75 \%$ and the $25 \%$ of the maximum HRR caused by the high-temperature stage of the combustion process. This ignition delay is also experimentally obtained.

$t_{i, 1-i n i}$ and $t_{i, 2-i n i}$ from chemical kinetic simulations are defined by means of the first stage of the combustion process (when the combustion energy starts to be released) because of the high differences in terms of maximum pressure rise rate that exist between experiments and CHEMKIN. An example of such modeling results can be seen in Fig. 3, in which the different pressure traces obtained experimentally and by simulation have been plotted.

Ignition delays under constant conditions $\left(\tau_{1}, \tau_{2}\right.$ and $\left.\tau_{C C}\right)$ and critical concentrations have been obtained by solving each chemical kinetic mechanism in a perfectly stirred reactor (PSR), which is a closed homogeneous reactor available in CHEMKIN. The PSR works at constant pressure and solves the energy equation to obtain the temperature evolution, and it is the most appropriate reactor to obtain ignition delays under constant pressure and temperature conditions [44].

Ignition delays under transient conditions $\left(t_{i, 1-i n i}\right.$ and $\left.t_{i, 2-i n i}\right)$ have been obtained by solving each chemical kinetic mechanism in a IC-engine model, which is a closed 0-D reciprocating internal combustion engine reactor available in CHEMKIN that works with homogeneous charge. The volume evolution and the heat losses evolution are imposed in order to replicate the RCEM conditions. The piston starts at Bottom Dead Center (BDC) and a complete cycle of the RCEM is simulated. The ignition of the mixture coincides with the criterion used in the experiments and, therefore, it allows comparing the simulated ignition delays directly with the experimental mea- 
surements. The results obtained from the IC-engine model performing the direct chemical kinetic calculation will be named as simulations further on.

Finally, each experiment has been discretized in successive thermodynamic states with a $\Delta t$ of $10^{-5} \mathrm{~s}$, obtaining the ignition delays under constant conditions and the critical concentrations for each state in a PSR. This value of the time step represents an equilibrium between appropriate prediction accuracy and reasonable calculation time. Besides, the maximum waiting time for the autoignition of the mixture in the PSR has been set to $30 \mathrm{~s}$.

\subsection{Parametric study performed}

The performed parametric study can be seen in Table 3. The tested fuel was n-dodecane, the main physiscochemical properties of which are summarized in Appendix B. The selected stroke was $180 \mathrm{~mm}$, while two compression ratios, $C R$, was tested: 14 and 19. The initial pressure was equal to $1.5 \mathrm{bar}$, while the injection pressure is 500 bar for all cases. Finally, despite the fact that the initial temperature is lower than the boiling point of the n-dodecane, the filling time $(\approx 40 s)$ is long enough to ensure the complete vaporization of the fuel before the beginning of the compression stroke for the fuel/air ratios considered in the present investigation.

\section{Results and discussion}

In this section, ignition delays are obtained by solving the five chemical kinetic mechanisms described in Table 2. The results from simulations are compared to the experimental measurements as a method to validate the mechanisms in the working range. Moreover, the variability between 


\begin{tabular}{|c|c|c|c|c|}
\cline { 3 - 5 } \multicolumn{2}{c|}{} & \multicolumn{3}{|c|}{$X_{O_{2}}[-]$} \\
\cline { 2 - 5 } & $\mathbf{0 . 2 1}$ & $\mathbf{0 . 1 8}$ & $\mathbf{0 . 1 6}$ \\
\hline \multirow{4}{*}{$T_{i}[K]$} & $\mathbf{4 0 3}$ & $0.4,0.5,0.6$ & $0.4,0.5,0.6$ & \\
\cline { 2 - 5 } & $\mathbf{4 2 3}$ & $0.4,0.5,0.6$ & $0.4,0.5,0.6$ & $0.5,0.6,0.7$ \\
\cline { 2 - 5 } & $\mathbf{4 4 3}$ & $0.4,0.5,0.6$ & $0.4,0.5,0.6$ & \\
\cline { 2 - 5 } & $\mathbf{4 6 3}$ & $0.4,0.5,0.6$ & $0.4,0.5,0.6$ & $0.5,0.6,0.7$ \\
\hline
\end{tabular}

Table 3: Parametric study performed. Equivalence ratio for different initial temperatures and oxygen molar fractions.

mechanisms is also quantified. The experimental ignition delay trends of ndodecane are discussed in Appendix C, providing experimental data of the ignition characteristics of this fuel under engine conditions, which are not available in the literature. Furthermore, the experimental ignition delay is also intended to be predicted using the integral procedure proposed by Desantes et al. already presented in this paper (Eqs. 2 and 3). The predictive procedure is tested with five different databases (each one from a different chemical kinetic mechanism), studying the sensitivity of the method. Finally, the predictive capability of the integral procedure is compared to the accuracy of the chemical simulations.

\subsection{Variability and validation of the different chemical kinetic mechanisms}

The five chemical kinetic mechanisms summarized in Table 2 have been tested by solving an internal combustion engine reactor in CHEMKIN that replicates the in-cylinder conditions reached in the RCEM. Besides, the relative ignition delay deviation, $\epsilon$, has been calculated in order to more easily compare experimental and simulation results. This deviation is defined as 
follows:

$$
\epsilon=\frac{t_{i, n-i n i X}-t_{i, n-i n i R C E M}}{t_{\text {compression }}} 100
$$

where $t_{i, n-i n i}$ can represent either a ignition delay under transient thermodynamic conditions referred to cool flames, $n=1$, or referred to the hightemperature stage, $n=2$. The subscript $X$ represents data obtained from a CHEMKIN simulation solving each one of the tested chemical kinetic mechanisms. Finally, the subscript $R C E M$ represents data obtained experimentally from the RCEM. The compression time has been chosen as the way to normalize the ignition delay deviations, since ignition delays under engine conditions have been obtained in this investigation. Thus, a relative deviation in $\mathrm{CAD}$ is much more interesting than a relative deviation respect to the measured ignition delay, and it can be easily obtained if the deviation is normalized by means of the compression time. In fact, the ignition delay deviation in CAD can be simply calculated as $\Delta \theta[C A D]=1.80 \epsilon$, where $\epsilon$ represents the ignition delay deviation in percent ([\%]) normalized by means of the compression time. Thus, the consequences of the deviations between experiments and simulations on the engine can be more easily interpreted.

The ignition delay deviations between the simulations and the measurements are shown in Fig. 4 versus the experimental ignition delay for all the tested mechanisms and both ignition stages. As already indicated and justified, the ignition delay based on the initial part of the HRR has been considered for the comparison. Fig. 4 to the left shows that the ignition delay deviation referred to cool flames seems to be more positive if the ignition delay is increased, i.e., if the reactivity of the mixture is decreased. The 

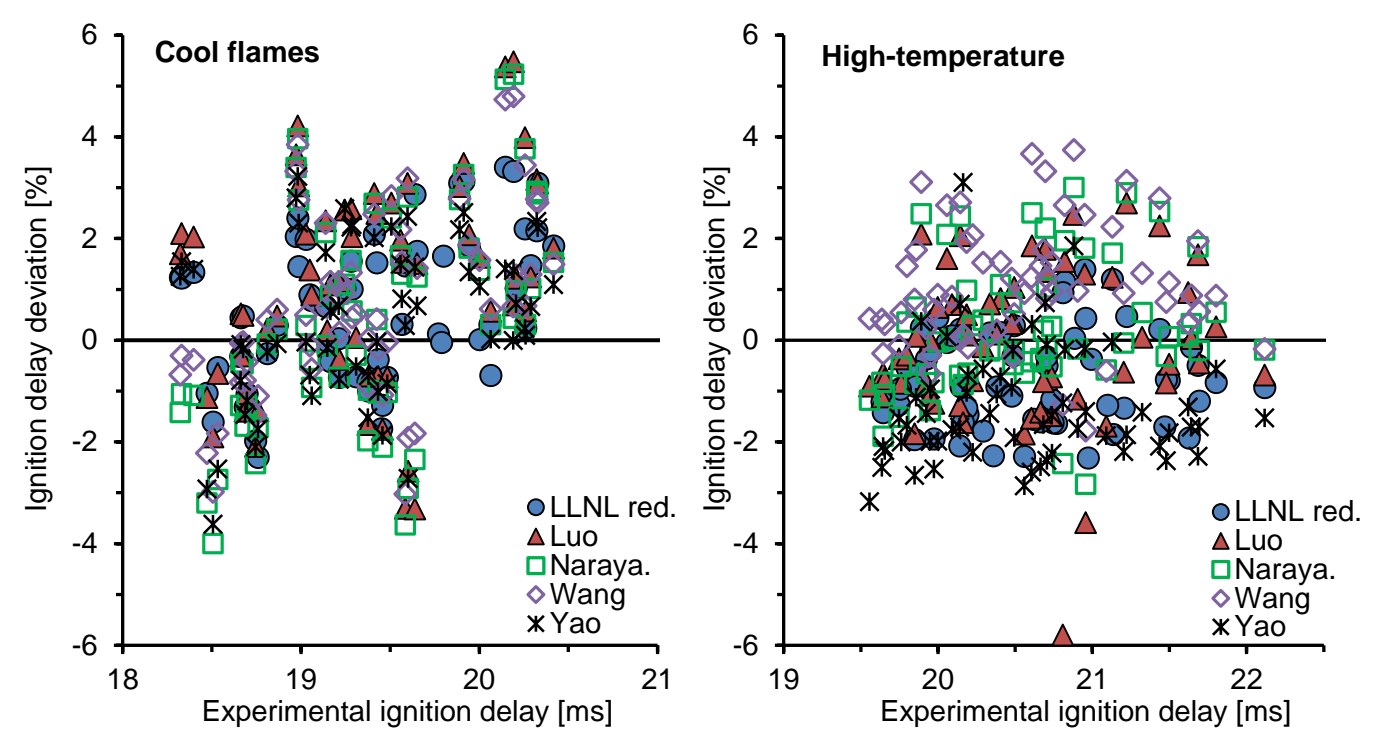

Figure 4: Ignition delay deviation for simulations versus experimental ignition delay measurements. Left.- Deviations referred to cool flames. Right.- Deviations referred to the high-temperature stage of the process. 
lower the reactivity the nearer the ignition to TDC. Besides, wall effects are more relevant near TDC because of the higher area-to-volume ratio of the combustion chamber. Thus, if the ignition occurs near TDC, the in-cylinder temperature gradients will be higher, leading to higher differences between the maximum local temperature and the mean temperature of the homogeneous gas bulk. Taking into account that cool flames are highly dependent on temperature and that the temperature in CHEMKIN corresponds to the mean temperature of the homogeneous gas core, the lower the reactivity the higher the differences between the experimental ignition delay referred to cool flames (defined by the maximum local temperature) and the simulated ignition delay referred to cool flames (defined by the mean temperature of the homogeneous gas bulk). Therefore, the lower the reactivity the more positive the ignition delay deviation according to Eq. 4, since shorter ignition delays will be obtained in the RCEM.

Fig. 4 to the right shows a random distribution of the ignition delay deviations referred to the high-temperature stage of the process. However, it can be seen that Yao's mechanism tends to under-predict the ignition delay $t_{i, 2-i n i}$, while Wang's mechanism tends to over-predict this parameter. The high-temperature stage of the ignition process is triggered by the $\mathrm{H}_{2} \mathrm{O}_{2}$ decomposition by means of the following reaction:

$$
\mathrm{H}_{2} \mathrm{O}_{2}+\mathrm{M}=\mathrm{OH}+\mathrm{OH}+\mathrm{M}
$$

which is a third body reaction in which $M$ represents any species that is able to stabilize the reaction. On the one hand, not only the specific reaction rate of reaction 5 , but also the $\mathrm{H}_{2} \mathrm{O}_{2}$ generation are enhanced in 
Yao's mechanism, leading to shorter ignition delays $t_{i, 2-i n i}$. On the other hand, the $\mathrm{H}_{2} \mathrm{O}_{2}$ generation is reduced in Wang's mechanisms due to the enhanced alternative chemical pathways for $\mathrm{HO}_{2}$, which is the main $\mathrm{H}_{2} \mathrm{O}_{2}$ generator. This causes a lower reaction rate of reaction 5, leading to longer ignition delays $t_{i, 2-i n i}$.

The confidence intervals for the mean absolute deviation, $|\bar{\epsilon}|=\sum|\epsilon| / N$, with a confidence level of $95 \%$ are summarized in Table 4 for all the tested mechanisms and both ignition stages. It can be seen that $t_{i, 2-i n i}$ is more accurately modeled than the ignition delay referred to cool flames, except for Yao's and Wang's, in which the modified specific reaction rates cause the opposite trend. However both ignition delays seems to be simulated with quite good accuracy.

\begin{tabular}{|c|c|c|c|c|}
\cline { 2 - 5 } \multicolumn{1}{c|}{} & \multicolumn{2}{c|}{ Cool flames } & \multicolumn{2}{c|}{ High-temperature stage } \\
\cline { 2 - 5 } \multicolumn{1}{c|}{} & $|\bar{\epsilon}|[\mathbf{\%}]$ & IC 95\% [\%] & $|\bar{\epsilon}|[\%]$ & IC 95\% [\%] \\
\hline LLNL reduced & 1.280 & {$[1.046-1.515]$} & 1.001 & {$[0.833-1.169]$} \\
\hline Luo & 1.892 & {$[1.571-2.213]$} & 1.139 & {$[0.895-1.385]$} \\
\hline Narayanaswamy & 1.757 & {$[1.431-2.082]$} & 0.990 & {$[0.767-1.213]$} \\
\hline Wang & 1.513 & {$[1.201-1.826]$} & 1.256 & {$[1.001-1.511]$} \\
\hline Yao & 1.335 & {$[1.093-1.578]$} & 1.538 & {$[1.329-1.747]$} \\
\hline
\end{tabular}

Table 4: Confidence interval for the mean absolute deviation, $|\bar{\epsilon}|$, with a confidence level of $95 \%$ for the chemical kinetic simulations.

54 Finally, the variability of the simulations is shown in Fig. 5, in which the coefficient of variation of the results obtained with the different chemical kinetic mechanisms is plotted versus the experimental ignition delay for both 


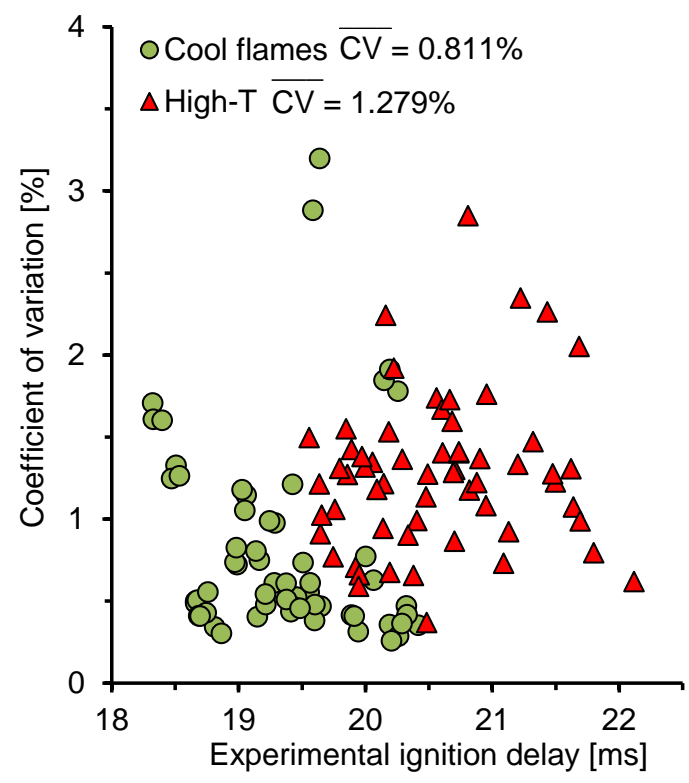

Figure 5: Coefficient of variation of the simulated ignition delay obtained by solving the different chemical kinetic mechanisms versus the experimental ignition delay for both ignition stages. 


\begin{tabular}{|l|c|c|}
\cline { 2 - 3 } \multicolumn{1}{c|}{} & $\overline{C V}$ cool flames [\%] & $\overline{C V}$ high-temperature stage [\%] \\
\hline \multicolumn{1}{c|}{ Experiments } & 0.253 & 0.318 \\
\hline $\begin{array}{l}\text { Direct chemical } \\
\text { kinetics calculation } \\
\text { (simulations) }\end{array}$ & 0.811 & 1.279 \\
\hline
\end{tabular}

Table 5: Average coefficient of variation of the results obtained with the different chemical kinetic mechanisms and average coefficient of variation of the experimental data.

ignition stages. The average coefficient of variation, $\overline{C V}$, has been calculated and its value is also presented in the figure. Besides, the variability of the simulations can be analyzed by comparing $\overline{C V}$ to the corresponding value from the experiments, which is also a measurement of the repeatability of the RCEM, obtaining the results presented in Table 7.

Despite the fact that the coefficient of variation of the simulated ignition delay is low, it can be seen that it is significantly higher than the corresponding value from the experiments, which means that the chemical kinetic mechanisms lead to results different enough to be able to distinguish different simulated ignition delays depending on the used mechanism.

\subsection{Sensitivity analysis and validation of the predictive procedure}

The five chemical kinetic mechanisms summarized in Table 2 have been solved for the generation of five different databases of ignition delays and critical concentrations under constant conditions, which have been used to predict the ignition delay with the alternative procedure defined by Eqs. 2 and 3. In this case, in order to be consistent with the predictive procedure, the ignition delay $\left(t_{i, 1-\max }\right.$ or $t_{i, 2-\max }$ for cool flames and high-temperature, respectively) is defined as the time between the beginning of the rapid com- 

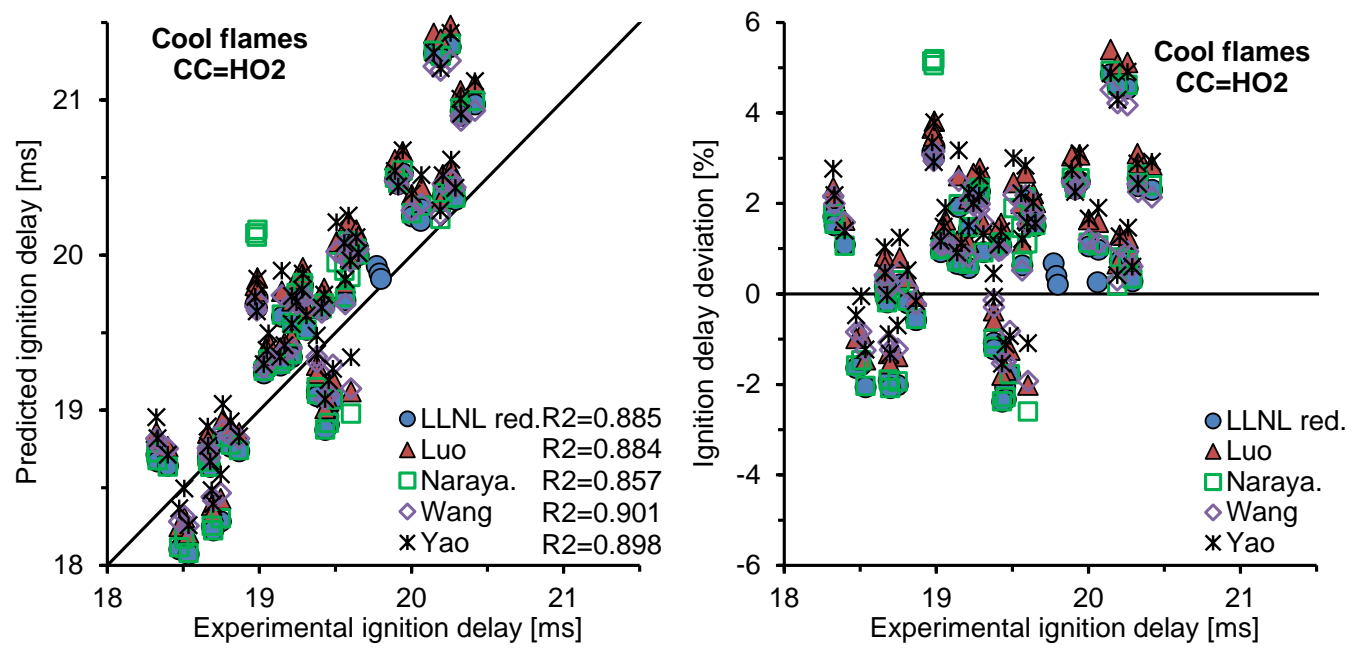

Figure 6: Predicted ignition delay and ignition delay deviation referred to cool flames using $\mathrm{HO}_{2}$ as chain carrier versus experimental ignition delay measurements. Left.- Predictions. Right.- Deviations.

pression stroke and the instant at which a peak of the pressure rise rate signal occurs. The relative ignition delay deviation, $\epsilon$, which has been analogously defined as in Eq. 4, has been calculated in order to more easily compare predictions and measurements.

The ignition delay predictions and ignition delay deviations are shown in Fig. 6 versus the experimental ignition delay referred to cool flames using the five different databases (from each of the tested mechanisms). As already explained in Section 2.2, $\mathrm{HO}_{2}$ takes the role of chain carrier for the prediction of cool flames. The line $y=x$, which represents a perfect match between values, has been also represented in the figure to the left. Besides, the Pearson's coefficient of correlation, $R^{2}$, has been calculated for each mechanism and its value has also been added to the figure to the left. It can be seen that 

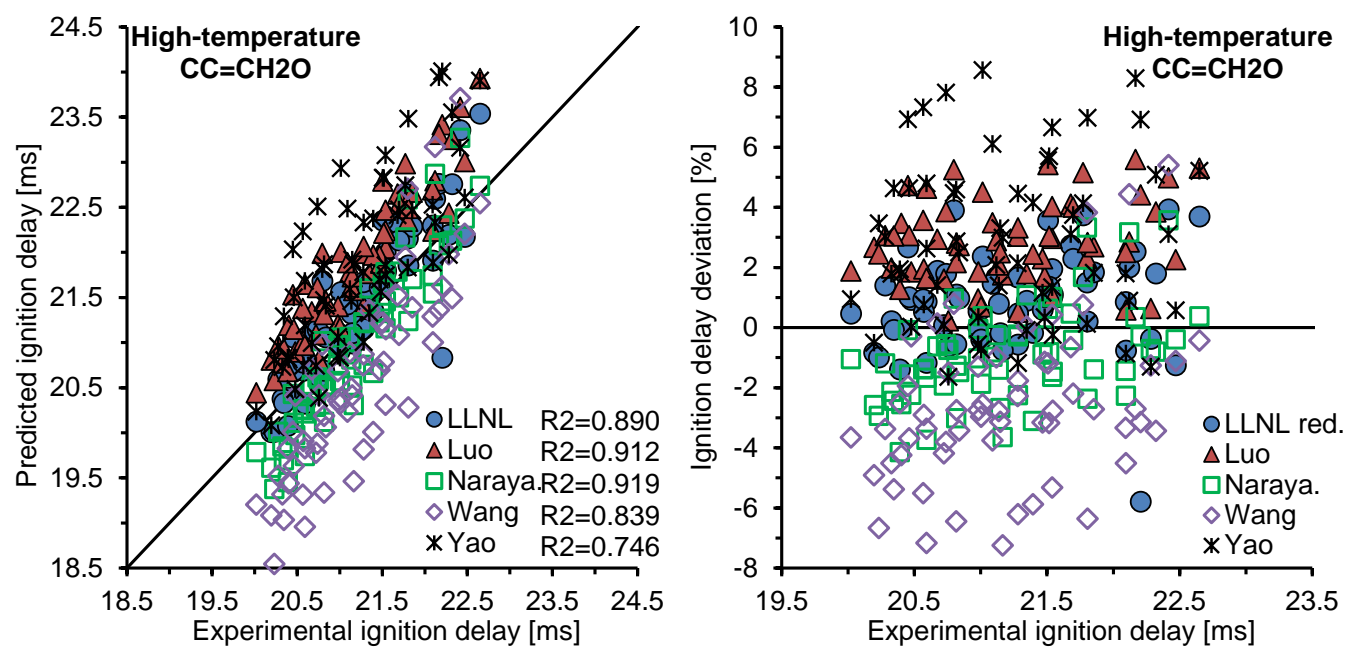

Figure 7: Predicted ignition delay and ignition delay deviation referred to the hightemperature stage using $\mathrm{CH}_{2} \mathrm{O}$ as chain carrier versus experimental ignition delay measurements. Left.- Predictions. Right.- Deviations.

cool flames are slightly over-predicted. This is because Eq. 2 assumes that the accumulation rate of chain carriers follows a zero-order reaction, while it actually has an exponential behavior with time. This implies that more time is needed in Eq. 2 to reach the critical concentration, leading to longer predicted ignition delays.

The ignition delay predictions and ignition delay deviations are shown in Fig. 7 versus the experimental ignition delay referred to the high-temperature stage of the process using the five different databases (from each of the tested mechanisms). In a first attempt, $\mathrm{CH}_{2} \mathrm{O}$ takes the role of chain carrier (as explained in Section 2.2) for the prediction of the high exothermic stage. The line $y=x$ has been also represented in the figure to the left, as well as the Pearson's coefficient of correlation, $R^{2}$, for each mechanism. As it can be 

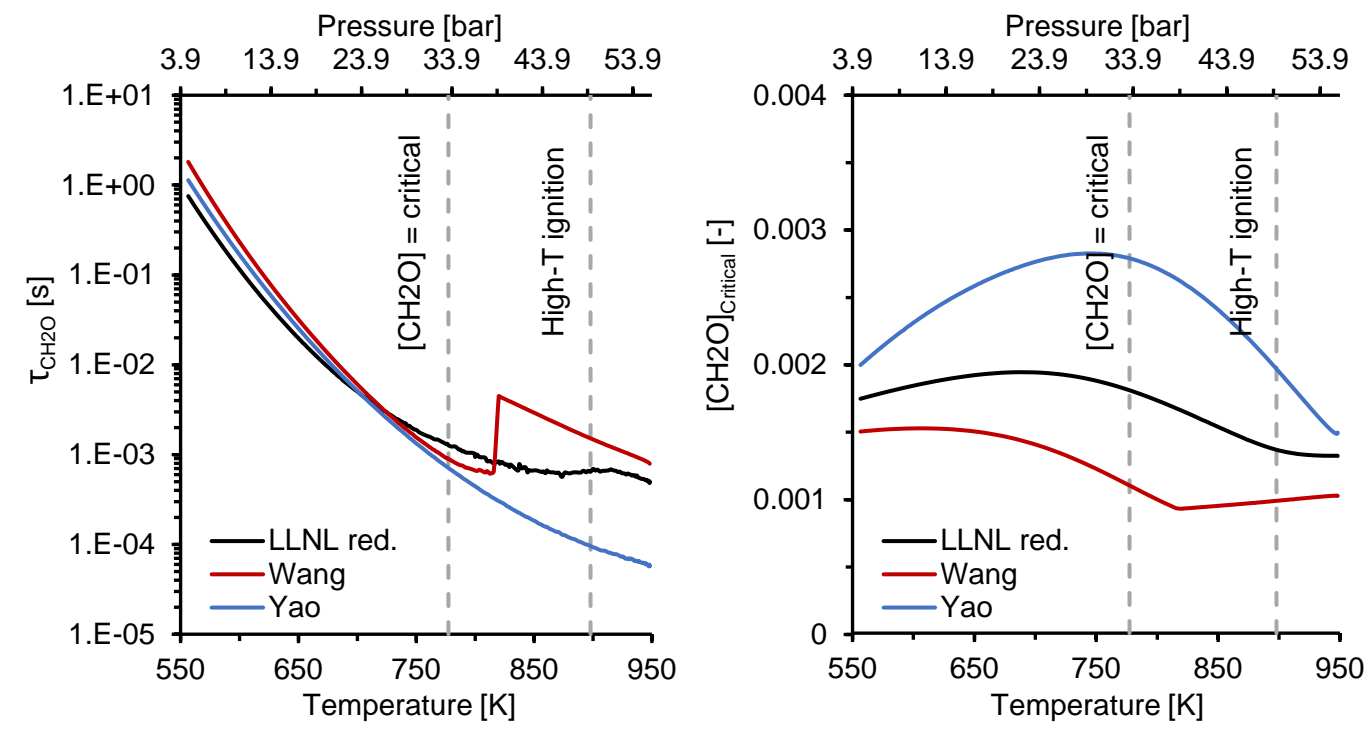

Figure 8: Database of ignition delays and critical concentrations under constant conditions referred to $\mathrm{CH}_{2} \mathrm{O}$ versus in-cylinder temperature and pressure for $\mathrm{CR}=14, \mathrm{X}_{\mathrm{O}_{2}}=0.18$, $\mathrm{T}_{i}=443 \mathrm{~K}$ and $\mathrm{Fr}=0.5$. Three different chemical kinetic mechanisms have been plotted. Left.- $\tau_{C C}$ function. Right.- $[C C]_{\text {crit }}$ function.

seen, the LLNL reduced, Luo's and Narayanaswamy's mechanisms lead to the best predictions, while Yao's and Wang's mechanisms tend to over and under-predict the ignition time, respectively. Moreover, predictions obtained with databases generated from LLNL reduced, Luo's and Narayanaswamy's mechanisms are similar to each other. This is an expected result, since these three mechanisms are based on the same detailed chemical kinetic mechanism for n-alkanes from Lawrence Livermore National Laboratories [45].

The databases obtained from Yao's and Wang's chemical mechanisms have been compared to the database generated from the LLNL reduced mechanism in order to identify what causes the over and under-prediction 
of the ignition time, respectively. Fig. 8 shows such comparison versus the in-cylinder conditions reached for $\mathrm{CR}=14, \mathrm{X}_{\mathrm{O}_{2}}=0.18, \mathrm{~T}_{i}=443 \mathrm{~K}$ and $\mathrm{Fr}=0.5$. Besides, the predicted ignition times referred to a critical concentration of chain carriers (Eq. 2) and referred to the high-temperature stage (Eq. 3) using the database of the LLNL reduced mechanism have been also represented in the figure. Fig. 8 shows a sudden increase in the $\tau_{C C}$ function obtained by the Wang's mechanism, as well as a no differentiable point in the $[C C]_{\text {crit }}$ function. This is caused by the interaction between the lowtemperature chain branching and the high-temperature mechanisms, which can be not very accurately described in skeletal chemical kinetic mechanisms.

Regarding Eq. 2, it can be seen in Fig. 8 that the ignition delay is very similar for the three databases before reaching the critical concentration of $\mathrm{CH}_{2} \mathrm{O}$. However, the critical concentration of formaldehyde increases for Yao's, while it decreases for Wang's during the same time interval. A positive rise rate of the $[C C]_{\text {crit }}$ function means a slower accumulative behavior in Eq. 2, which leads to longer ignition delays referred to a critical concentration of chain carriers, and vice versa. As for Eq. 3, it can be seen in Fig. 8 that the ignition delay is shorter for Yao's, while it is longer for Wang's in the time interval between the point where the critical concentration of $\mathrm{CH}_{2} \mathrm{O}$ is reached and that where the high-temperature ignition occurs. A shorter $\tau_{C C}$ function means a slower consumption behavior in Eq. 3, which leads to longer ignition delays referred to the high-temperature stage of the process, and vice versa. Therefore, while Yao's mechanism over-predicts the ignition delay, Wang's mechanisms under-predicts such parameter.

In a second attempt, $\mathrm{H}_{2} \mathrm{O}_{2}$ has been selected as an alternative autoigni- 

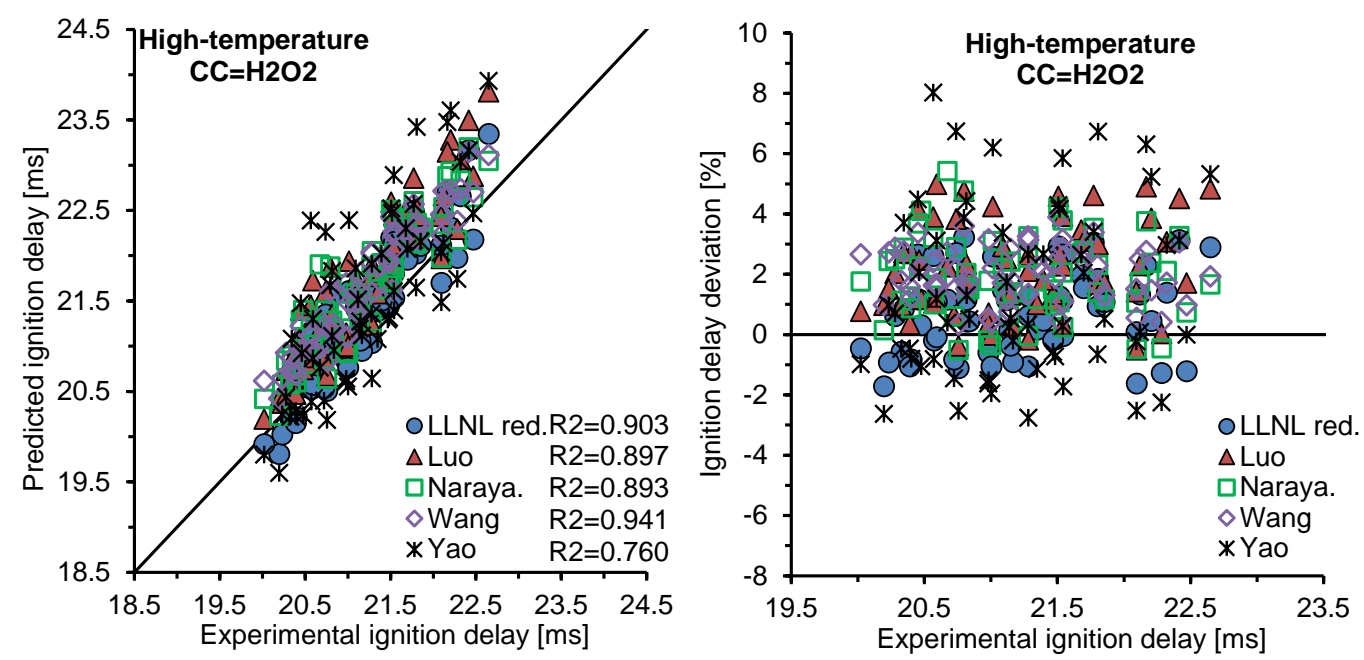

Figure 9: Predicted ignition delay and ignition delay deviation referred to the hightemperature stage using $\mathrm{H}_{2} \mathrm{O}_{2}$ as chain carrier versus experimental ignition delay measurements. Left.- Predictions. Right.- Deviations.

tion tracer in order to correct the over and under-estimation of the ignition delay by using the Yao's and Wang's mechanisms, respectively. The ignition delay predictions and ignition delay deviations are shown in Fig. 9 versus the experimental ignition delay referred to the high-temperature stage of the process using the five different databases, in which $\mathrm{H}_{2} \mathrm{O}_{2}$ takes the role of chain carrier. The line $y=x$ has been also represented in the figure to the left, as well as the Pearson's coefficient of correlation, $R^{2}$. As it can be seen, the ignition delay deviation shows a random distribution, avoiding the deviations trends that could be seen for formaldehyde in Fig. 7.

Fig. 10 shows LLNL reduced, Yao's and Wang's databases referred to $\mathrm{H}_{2} \mathrm{O}_{2}$ versus the in-cylinder conditions reached for $\mathrm{CR}=14, \mathrm{X}_{\mathrm{O}_{2}}=0.18$, $\mathrm{T}_{i}=443 \mathrm{~K}$ and $\mathrm{Fr}=0.5$. As it can be seen for both Yao's and Wang's 

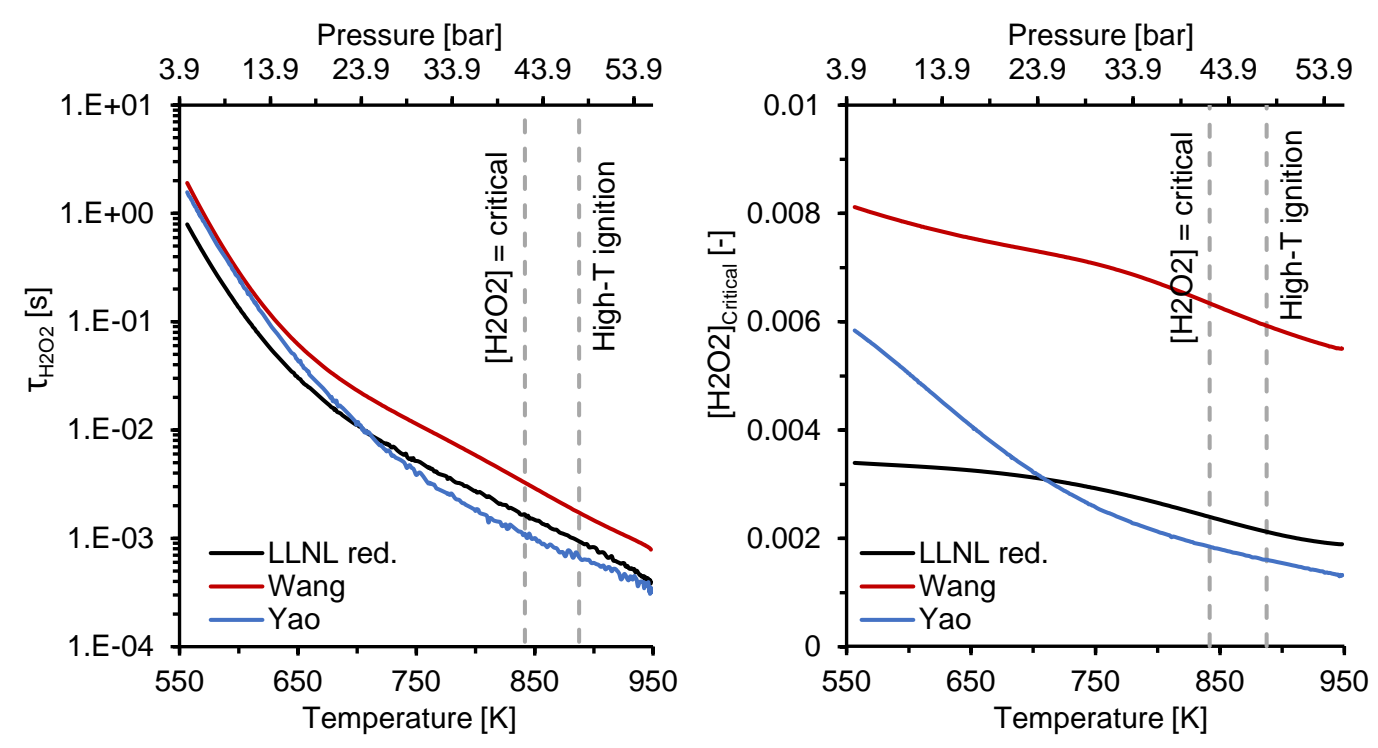

Figure 10: Database of ignition delays and critical concentrations under constant conditions referred to $\mathrm{H}_{2} \mathrm{O}_{2}$ versus in-cylinder temperature and pressure for $\mathrm{CR}=14, \mathrm{X}_{\mathrm{O}_{2}}=$ $0.18, \mathrm{~T}_{i}=443 \mathrm{~K}$ and $\mathrm{Fr}=0.5$. Three different chemical kinetic mechanisms have been plotted. Left.- $\tau_{C C}$ function. Right.- $[C C]_{\text {crit }}$ function. 
mechanisms, non-differentiable points are avoided in the functions because of a better description of the $\mathrm{H}_{2} \mathrm{O}_{2}$ evolution. Besides, the $[C C]_{\text {crit }}$ decreasing rates above $700 \mathrm{~K}$ are very similar to each other for all databases. Thus, the over and under-estimation of the ignition delay by using the Yao's and Wang's mechanisms, respectively, is solved when $\mathrm{H}_{2} \mathrm{O}_{2}$ takes the role of chain carrier.

The confidence intervals for the mean absolute deviation, $|\bar{\epsilon}|=\sum|\epsilon| / N$, with a confidence level of $95 \%$ are summarized in Table 6 for all the tested mechanisms and both ignition stages. It can be seen that $t_{i, 1-\max }$ is more accurately predicted than the ignition delay referred to the high-temperature stage, since the uncertainties associated to Eq. 3 are not included in cool flames predictions. Moreover, using $\mathrm{H}_{2} \mathrm{O}_{2}$ as autoignition tracer leads to significantly better predictions than using $\mathrm{CH}_{2} \mathrm{O}$.

\begin{tabular}{|c|c|c|c|c|c|c|}
\cline { 2 - 8 } \multicolumn{1}{c|}{} & \multicolumn{2}{c|}{ Cool flames } & \multicolumn{2}{c|}{ High-temperature stage } & \multicolumn{2}{c|}{ High-temperature stage } \\
\cline { 2 - 8 } \multicolumn{1}{c|}{$\left(C C=\mathrm{HO}_{2}\right)$} & \multicolumn{2}{c|}{$\left(C C=\mathrm{CH}_{2} \mathrm{O}\right)$} & \multicolumn{2}{|c|}{$\left(C C=\mathrm{H}_{2} \mathrm{O}_{2}\right)$} \\
\cline { 2 - 8 } \multicolumn{1}{c|}{$|\bar{\epsilon}|[\%]$} & IC 95\%[\%] & $|\bar{\epsilon}|[\%]$ & IC 95\% [\%] & $|\bar{\epsilon}|[\%]$ & IC 95\% [\%] \\
\hline LLNL reduced & 1.580 & {$[1.296-1.864]$} & 1.371 & {$[1.069-1.673]$} & 1.219 & {$[0.989-1.449]$} \\
\hline Luo & 1.927 & {$[1.628-2.226]$} & 2.824 & {$[2.478-3.171]$} & 2.193 & {$[1.819-2.568]$} \\
\hline Narayanaswamy & 1.769 & {$[1.437-2.101]$} & 1.507 & {$[1.231-1.783]$} & 1.970 & {$[1.653-2.287]$} \\
\hline Wang & 1.552 & {$[1.293-1.812]$} & 3.168 & {$[2.682-3.654]$} & 2.000 & {$[1.771-2.230]$} \\
\hline Yao & 1.768 & {$[1.473-2.063]$} & 3.066 & {$[2.447-3.684]$} & 2.356 & {$[1.837-2.874]$} \\
\hline
\end{tabular}

Table 6: Confidence interval for the mean absolute deviation, $|\bar{\epsilon}|$, with a confidence level of $95 \%$ for the predictive procedure. The five different databases are shown in the table.

48 Finally, the variability of the predictions is shown in Fig. 11, in which the coefficient of variation of the results obtained with the different databases is plotted versus the experimental ignition delay for both ignition stages. 


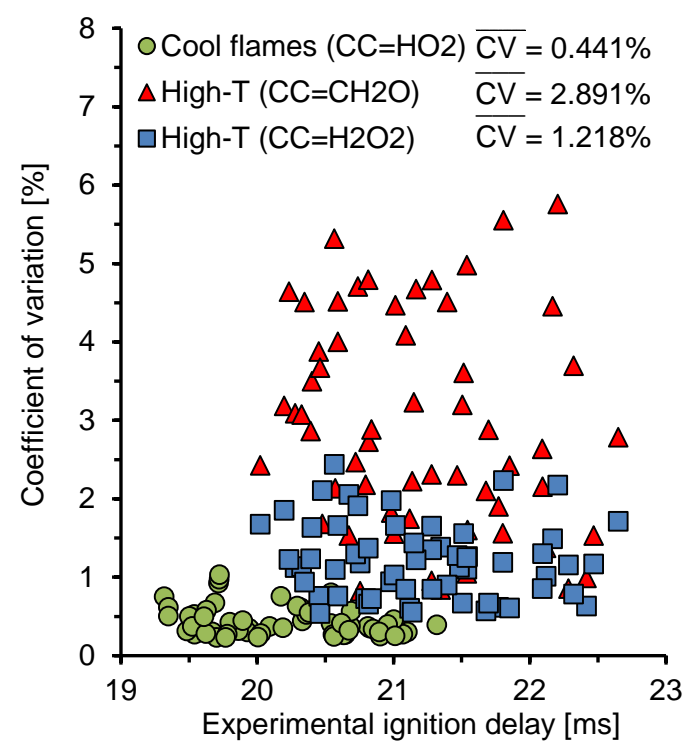

Figure 11: Coefficient of variation of the predicted ignition delay obtained by using the different databases from the tested chemical kinetic mechanisms versus the experimental ignition delay for both ignition stages. 


\begin{tabular}{|c|c|c|}
\cline { 2 - 3 } \multicolumn{1}{c|}{} & $\overline{C V}$ cool flames [\%] & $\overline{C V}$ high- temperature stage [\%] \\
\hline Experiments & 0.253 & 0.318 \\
\hline $\begin{array}{l}\text { Direct chemical } \\
\text { kinetics calculation } \\
\text { (simulations) }\end{array}$ & 0.811 & 1.279 \\
\hline $\begin{array}{l}\text { Integral method } \\
\text { calculation (predictions) }\end{array}$ & $0.441\left(\mathrm{CC}=\mathrm{HO}_{2}\right)$ & $2.891\left(\mathrm{CC}=\mathrm{CH}_{2} \mathrm{O}\right)$ \\
\cline { 2 - 3 } & & $1.218\left(\mathrm{CC}=\mathrm{H}_{2} \mathrm{O}_{2}\right)$ \\
\hline
\end{tabular}

Table 7: Average coefficient of variation of the results obtained with the different chemical kinetic mechanisms using both chemical kinetic simulations and predictive procedures, and average coefficient of variation of the experimental data.

The average coefficient of variation, $\overline{C V}$, has been calculated and its value is also presented in the figure. It can be seen that the variability of the high-temperature stage prediction is much higher than the variability of cool flames. Moreover, the coefficient of variation is highly increased when $\mathrm{CH}_{2} \mathrm{O}$ is used as chain carrier. The sensitivity of the predictive procedure is analyzed by comparing $\overline{C V}$ to the corresponding value from the simulations and the experiments, obtaining the results presented in Table 7.

It can be seen that the coefficient of variation of the predicted ignition delays referred to cool flames is really low, which means that cool flames can be predicted obtaining similar results whatever the chemical kinetic mechanism used for the generation of the needed database. However, Eq. 3 seems to be very sensitive to the species assumed as autoignition tracer. Thus, if $\mathrm{CH}_{2} \mathrm{O}$ takes the role of chain carrier, very different results are obtained by varying the database, i.e., by varying the chemical kinetic mechanism. However, the same degree of variability than the one referred to the simulations is obtained when $\mathrm{H}_{2} \mathrm{O}_{2}$ acts as chain carrier. Therefore, $\mathrm{H}_{2} \mathrm{O}_{2}$ is recommended 
to be used as a tracer of the high-temperature ignition in order to obtain the same differences in the predictions than the ones obtained in the simulations.

\section{Conclusions}

A predictive procedure for both high-temperature and cool flames ignition delays based on the accumulation and consumption of chain carriers has been validated for n-dodecane in this investigation. The measured ignition delays have been compared to results from chemical kinetic simulations performed in CHEMKIN and to results obtained by applying the predictive procedure, which results in ignition delay deviations below $2 \%$ and $2.5 \%$ for both simulations and predictions referred to cool flames $\left(\mathrm{HO}_{2}\right.$ as tracer) and to the high-temperature stage of the process $\left(\mathrm{H}_{2} \mathrm{O}_{2}\right.$ as tracer), respectively. However, predicted ignition delay deviations referred to the high-temperature ignition can be increased up to $3.2 \%$ if $\mathrm{CH}_{2} \mathrm{O}$ is assumed as chain carrier.

Different chemical kinetic mechanisms have been solved in order to characterize the variability of the simulations, while different databases have been generated in order to analyze the variability of the predictions. It was found that simulations are different enough to distinguish the different chemical kinetic mechanisms. Besides, while predicted cool flames seem to be independent on the selected database, the predicted high-temperature ignition delay is very sensitive to the species selected as chain carrier. Thus, if $\mathrm{CH}_{2} \mathrm{O}$ is assumed as ignition tracer, the coefficient of variation of the predicted ignition time for the different databases is equal to $3 \%$, while this percent decreases up to $1.3 \%$ when $\mathrm{H}_{2} \mathrm{O}_{2}$ takes the role of chain carrier.

The following conclusions can be deduced from this study: 
- The criterion to define the ignition should be carefully selected, since additional deviations caused by the ignition delay definition can be present because of the absence of wall effects in the CHEMKIN 0-D simulations.

- Despite the fact that the ignition delay deviations obtained by solving each of the chemical mechanisms are low, the variability of the modeled ignition delay is higher than the variability of the experimental measurements. Thus, different chemical kinetic mechanisms lead to different simulated ignition times, and the difference is significant.

- The predictive procedure seems to have similar accuracy than the chemical simulations by assuming $\mathrm{HO}_{2}$ as the cool flames tracer and $\mathrm{H}_{2} \mathrm{O}_{2}$ as the high-temperature ignition tracer. Regarding cool flames, the predictive procedure seems to be independent on the selected mechanism, being all the predicted ignition delays very similar to each other. As for the high-temperature ignition delay, if two chemical kinetic mechanisms that lead to different modeled ignition delays are used to generate two databases of $\tau$ and $[C C]_{\text {crit }}$ and the predictive procedure defined by Eq. 2 and Eq. 3 is solved, the predicted ignition delays will be different in the same order of magnitude than the simulated ones are different. 
710

711 712 713 714 715 716 717 718 719 720

$\begin{array}{ll}B D C & \text { Bottom Dead Center } \\ C A D & \text { Crank Angle Degrees } \\ C C & \text { Chain carriers } \\ C F D & \text { Computational Fluid Dynamics } \\ C I & \text { Compression Ignition } \\ \text { 721 } & \text { Compression Ratio } \\ c r i t & \text { Referred to a maximum concentration of chain carriers } \\ C V & \text { Coefficient of variation } \\ E C U & \text { Engine Control Unit } \\ E G R & \text { Exhaust Gas Recirculation } \\ F r & \text { Working equivalence ratio }\end{array}$

\section{Acknowledgements}

The authors would like to thank different members of the CMT-Motores Térmicos team of the Universitat Politècnica de València for their contribution to this work. The authors would also like to thank the member of ITQ, Joaquín Martinez, for his help with the gas chromatography. The authors are grateful to the Generalitat Valenciana for the financial support to acquire the RCEM (references PPC/2013/011 and FEDER Operativo 2007/2013 F07010203PCI00CIMETUPV001). Finally, the authors would like to thank the Spanish Ministry of Education for financing the PhD. Studies of Darío López-Pintor (grant FPU13/02329).

\section{Notation}




$\begin{array}{ll}H C C I & \text { Homogeneous Charge Compression Ignition } \\ H R R & \text { Heat Release Rate } \\ L T C & \text { Low Temperature Combustion } \\ N T C & \text { Negative Temperature Coefficient } \\ P_{i} & \text { Initial pressure } \\ P S R & \text { Perfectly Stirred Reactor } \\ R C C I & \text { Reactivity Controlled Compression Ignition } \\ R C E M & \text { Rapid Compression-Expansion Machine } \\ S I & \text { Spark Ignition } \\ T_{i} & \text { Initial temperature } \\ T D C & \text { Top Dead Center } \\ t_{i} & \text { Ignition delay under transient conditions } \\ t_{i, C C} & \text { Ignition delay under transient conditions referred to the crit- } \\ & \text { ical concentration of chain carriers } \\ t_{i, 1-i n i} & \text { Ignition delay under transient conditions referred to the start } \\ & \text { of the HRR of cool flames } \\ t_{i, 2-i n i} & \text { Ignition delay under transient conditions referred to the start } \\ & \text { of the high-temperature HRR } \\ t_{i, 1-\text { max }} & \text { Ignition delay under transient conditions referred to the max- } \\ & \text { imum pressure rise rate caused by cool flames } \\ t_{i, 2-\text { max }} & \text { Ignition delay under transient conditions referred to the max- } \\ & \text { imum pressure rise rate caused by the high-temperature igni- } \\ & \text { tion }\end{array}$




$\begin{array}{ll}U H C & \text { Unburned hydrocarbons } \\ X_{\mathrm{O}_{2}} & \text { Oxygen molar fraction } \\ \epsilon & \text { Percentage deviation in ignition delay between experimental } \\ & \text { and simulation or predicted results } \\ |\bar{\epsilon}| & \text { Mean absolute deviation between experimental and simula- } \\ & \text { tion or predicted results } \\ & \text { Ignition delay under constant conditions of pressure and tem- } \\ & \text { perature } \\ \tau_{C C} & \text { Ignition delay under constant thermodynamic conditions re- } \\ & \text { ferred to the critical concentration of chain carriers } \\ \tau_{2} & \text { Ignition delay under constant thermodynamic conditions re- } \\ & \text { ferred to the maximum pressure rise }\end{array}$

\section{Appendix A. Schematic of the ignition delay predictive method}

The predictive procedure to obtain high and low-temperature ignition delays under transient thermodynamic conditions proposed by Desantes et al. [30] is based on the accumulation and consumption of chain carriers, relating the evolution of the chain carriers concentration to cool flames and to the high-exothermic stage of the process.

Fig. A.12 shows the relationship between different species and the HRR. It can be seen that the critical concentration of $\mathrm{HO}_{2}$ coincides with the maximum HRR referred to cool flames. Besides, it can be also seen that when $\mathrm{H}_{2} \mathrm{O}_{2}$ or $\mathrm{CH}_{2} \mathrm{O}$ are completely consumed, the maximum HRR referred to the high-temperature stage occurs. Thus cool flames can be predicted 


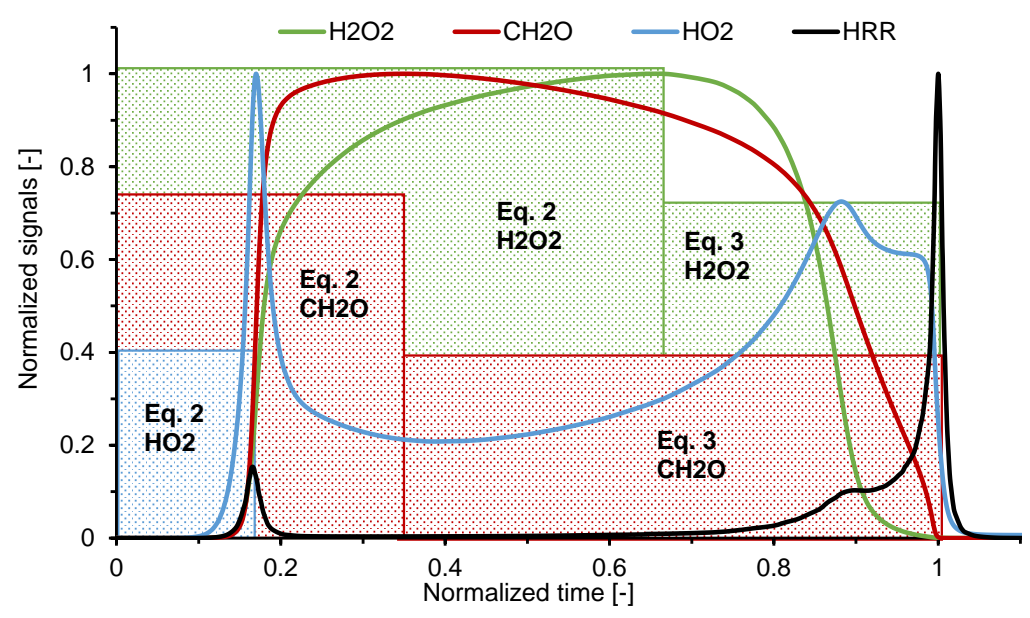

Figure A.12: Schematic of the predictive procedure. It can be seen that the ignition characteristics are referred to peaks of HRR (peaks of the pressure rise rate signal).

by modeling the accumulation behavior of $\mathrm{HO}_{2}$, while the high-exothermic stage can be predicted by modeling first the accumulation and then the consumption of $\mathrm{H}_{2} \mathrm{O}_{2}$ or $\mathrm{CH}_{2} \mathrm{O}$, indistinctly.

The method involves two different equations depending on the ignition stage to predict:

$$
\begin{aligned}
& 1=\frac{1}{[C C]_{\max , t_{i, C C}}} \int_{0}^{t_{i, C C}} \frac{[C C]_{\max }}{\tau_{C C}} d t \\
& 1=\frac{1}{[C C]_{\max , t_{i, C C}}} \int_{t_{i, C C}}^{t_{i, 2-\max }} \frac{[C C]_{\max }}{\tau_{2}-\tau_{C C}} d t
\end{aligned}
$$

where $t_{i, C C}$ is the ignition delay of the process referred to a maximum concentration of chain carriers and $t_{i, 2-\max }$ is the ignition delay referred to the maximum pressure rise rate caused by the high-temperature stage of combustion. Besides, $\tau_{2}, \tau_{C C}$ and $[C C]_{\max }$ are the ignition delay referred to the high 
exothermic stage, the ignition delay referred to a maximum of chain carriers and the critical concentration of chain carriers, respectively, under constant conditions of pressure and temperature for the successive thermodynamic states.

First, Eq. A.1 models the accumulation of chain carriers from the start of the process up to reach a critical concentration. Thus, ignition delays referred to a critical concentration of a certain species can be predicted by solving this integral. $\mathrm{HO}_{2}$ is suggested as chain carrier if the ignition delay referred to cool flames wants to be predicted, since the critical concentration of $\mathrm{HO}_{2}$ seems to be a good tracer of this phenomenon.

Secondly, Eq. A.2 models the consumption of chain carriers starting from their critical concentration. Thus, ignition delays referred to a complete consumption of chain carriers after reaching the critical concentration can be predicted by solving this integral. As already indicated previously, the chain carrier to be considered can be either $\mathrm{CH}_{2} \mathrm{O}$ or $\mathrm{H}_{2} \mathrm{O}_{2}$. It should be noted that the lower limit of integration in Eq. A.2 corresponds to the upper limit of integration in Eq. A.1, i.e., Eq. A.1 and Eq. A.2 are consecutive integrals. Thus, Eq. A.1 should be solved assuming $C C=\mathrm{CH}_{2} \mathrm{O}$ (or the species that takes the role of chain carrier for the prediction of the high-temperature ignition delay) in order to be able to compute Eq. A.2. It should be noted that if the fuel does not present a two-stage ignition, $\tau_{C C}$ and $\tau_{2}$ are virtually the same, and the ignition delays predicted for both integrals, $t_{i, C C}$ and $t_{i, 2-\max }$, are also virtually the same.

A schematic of the predictive procedure is also shown in Fig. A.12, where the time interval modeled by each integral is represented as a colored area in 
the figure. It can be seen that the method defines the start of ignition referred to cool flames $\left(t_{i, \mathrm{HO} 2}\right)$ as the maximum HRR caused by this phenomenon, i.e., as the peak of pressure rise rate, since the critical concentration of $\mathrm{HO}_{2}$ coincides with this peak. Moreover, it also defines the ignition delay referred to the high-temperature stage $\left(\tau_{2}, t_{i, 2-\max }\right)$ as the maximum HRR (or maximum pressure rise rate), since the species that takes the role of chain carrier is completely consumed when this peak occurs. Therefore, defining the start of ignition as the instant in which a peak of the pressure rise rate occurs is mandatory for a proper comparison between experiments and predictions, and this is the reason why this criterion to define the ignition delay is applied in this investigation.

\section{Appendix B. Physicochemical properties of n-dodecane}

The main physicochemical properties of the n-dodecane used in this investigation are summarized in Table B.8.

\section{Appendix C. Experimental autoignition characteristics of n-dodecane}

Ignition delays referred to the start of the HRR, $t_{i, 1-i n i}$ and $t_{i, 2-i n i}$, are shown in this section. However, it will be proved that the alternative definition based on a peak of the pressure rise rate signal leads to the same trends.

Fig. C.13 shows the ignition delay referred to the high-temperature stage of the process for different initial temperatures under several compression ratios, equivalence ratios and oxygen molar fractions. The ignition delay decreases if the initial temperature increases. However, the ignition delay 


\begin{tabular}{|c|c|}
\cline { 2 - 2 } \multicolumn{1}{c|}{} & N-dodecane \\
\hline Purity & $99.5 \%$ \\
\hline Density & $745 \mathrm{~kg} / \mathrm{m} 3$ \\
\hline Viscosity & $0.001362 \mathrm{~Pa} \cdot \mathrm{s}$ \\
\hline RON & -40 \\
\hline MON & -40 \\
\hline Boiling point & $488 \mathrm{~K}$ \\
\hline Heat capacity $C_{p}$ & $2.212 \mathrm{~kJ} / \mathrm{kg} \cdot \mathrm{K}$ \\
\hline Low heating value & $44.147 \mathrm{M} \mathrm{J} / \mathrm{kg}$ \\
\hline
\end{tabular}

Table B.8: Physicochemical properties of the n-dodecane tested in this investigation at $298 \mathrm{~K}$ and $1 \mathrm{bar}$.

decreasing rate is affected by the Negative Temperature Coefficient (NTC) behavior for a range of initial temperatures, which changes the slope of the curve. During the NTC zone, the formation of alkylperoxy species by the low-temperature chain branching mechanism competes with the formation of stable long-chain olefins by the alkyl radicals and alkyl hydroperoxides. Consequently, the NTC zone leads to a lower production of active radicals and chain carriers that causes a loss of reactivity and changes the ignition delay decreasing rate. Furthermore, as it can be seen for $\mathrm{CR}=19$, the ignition delay can even increase when the temperature is increased if the NTC behavior is strong enough.

Under the working conditions tested in this investigation, the range of initial temperatures that defines the NTC zone is:

- For $\mathrm{CR}=14$ : from $423 K$ to $443 K$. 

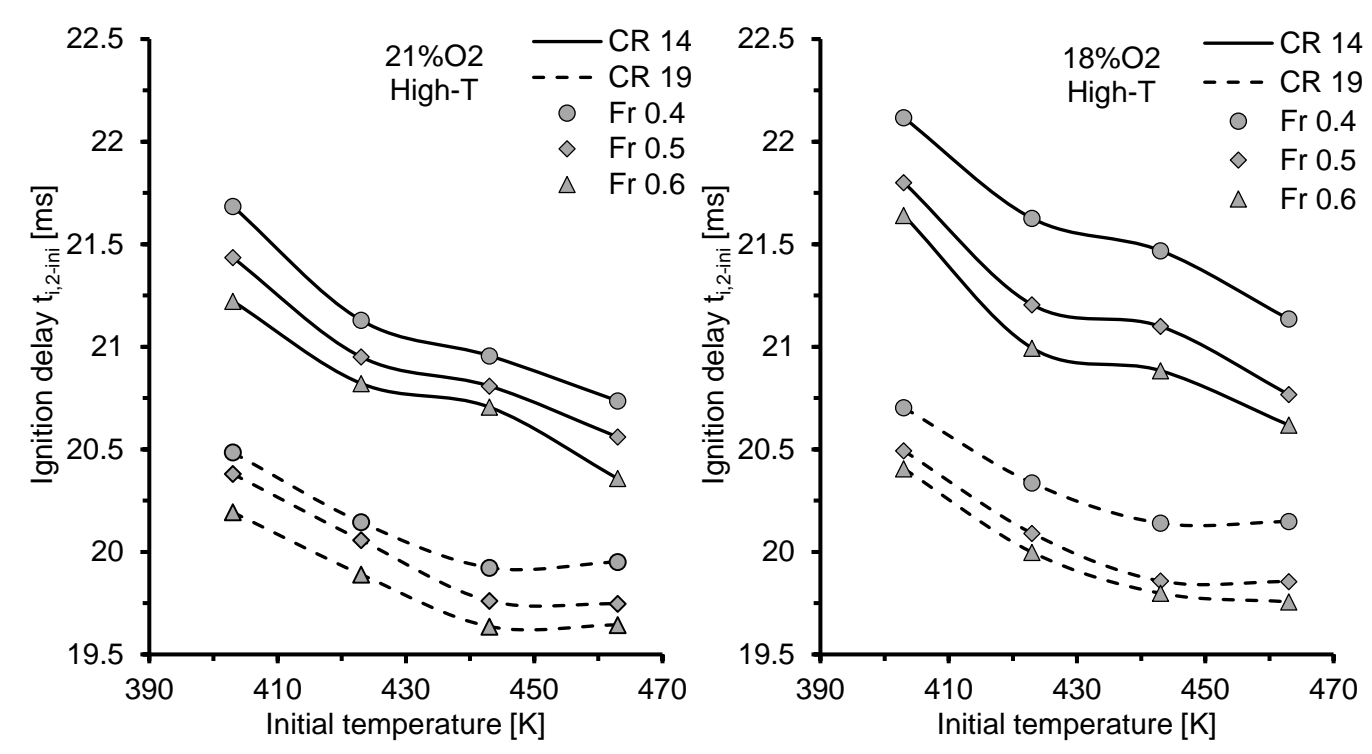

Figure C.13: Ignition delay, $t_{i, 2-i n i}$, versus initial temperature for different equivalence ratios. Both compression ratios are plotted. Left.- $\mathrm{X}_{\mathrm{O}_{2}}=0.21$. Right.- $\mathrm{X}_{\mathrm{O}_{2}}=0.18$.

- For $\mathrm{CR}=19$ : from $443 K$, the end of the NTC zone cannot be seen in the explored range.

Fig. C.13 also shows that the ignition delay referred to the high-temperature stage of the process decreases if the compression ratio is increased. This is an expected result, since higher compression ratios imply higher temperatures and pressures, which imply higher collision frequencies and collision energies, leading to faster reaction rates and, therefore, shorter ignition delays. Furthermore, the NTC zone is moved to higher initial temperatures if the compression ratio is increased because the pressure increases, since this phenomenon is controlled by unimolecular fall-off reactions that strongly depends on pressure. 
It can be seen in Fig. C.13 that the higher the equivalence ratio, the shorter the ignition delay referred to the high-temperature stage of the process. The autoignition phenomenon under low-temperature conditions is triggered by a critical concentration of chain carriers, which are generated directly from the fuel. Thus, the accumulation rate of chain carriers is increased if the equivalence ratio increases, leading to shorter ignition delays. Furthermore, the more dominant the low-temperature chain branching mechanism, the more relevant the effect of the equivalence ratio on the ignition delay. Thus, the ignition delay is more sensitive to changes in the equivalence ratio if the compression ratio is reduced, the equivalence ratio is reduced or the oxygen content is reduced (i.e., if the reactivity of the mixture is decreased).

Fig. C.13 and, more specifically, Fig. C.14 to the right show the dependence of the ignition delay, $t_{i, 2-i n i}$, on the oxygen content. As expected, the ignition delay referred to the high-temperature stage of the process increases if the oxygen molar fraction is decreased, since reducing the oxidizer implies reducing the reactivity. Furthermore, the more dominant the lowtemperature chain branching mechanism, the more relevant the effect of the oxygen content on the ignition delay. Thus, the ignition delay is more sensitive to changes in the oxygen content if the compression ratio is reduced, the initial temperature is reduced, the equivalence ratio is reduced or the oxygen content is reduced (i.e., if the reactivity of the mixture is decreased).

Regarding the cool flames, Fig. C.15 shows the ignition delay referred to this stage, $t_{i, 1-i n i}$, versus the initial temperature for different compression ratios, equivalence ratios and oxygen molar fractions. On the one hand, it can be seen that the ignition delay decreases when the initial temperature 

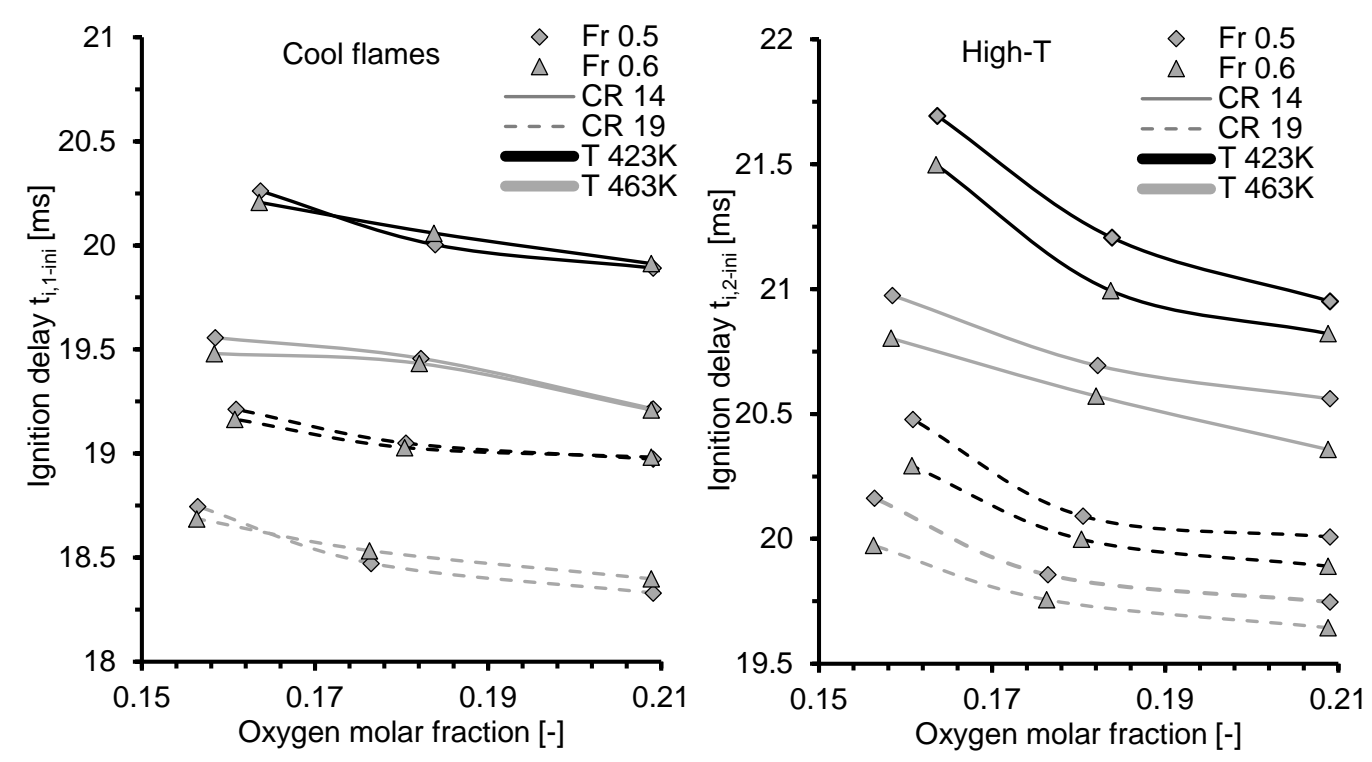

Figure C.14: Ignition delay versus molar fraction of oxygen for different conditions. Diamond marks.- $\mathrm{Fr}=0.5$. Triangular marks.- $\mathrm{Fr}=0.6$. Solid line.- $\mathrm{CR}=14$. Dashed line.- $\mathrm{CR}=19$. Black line.- $\mathrm{T}_{i}=423 \mathrm{~K}$. Grey line.- $\mathrm{T}_{i}=463 \mathrm{~K}$. Left.- Ignition delay referred to cool flames, $t_{i, 1-i n i}$. Right.- Ignition delay referred to the high-temperature stage, $t_{i, 2-i n i}$. 

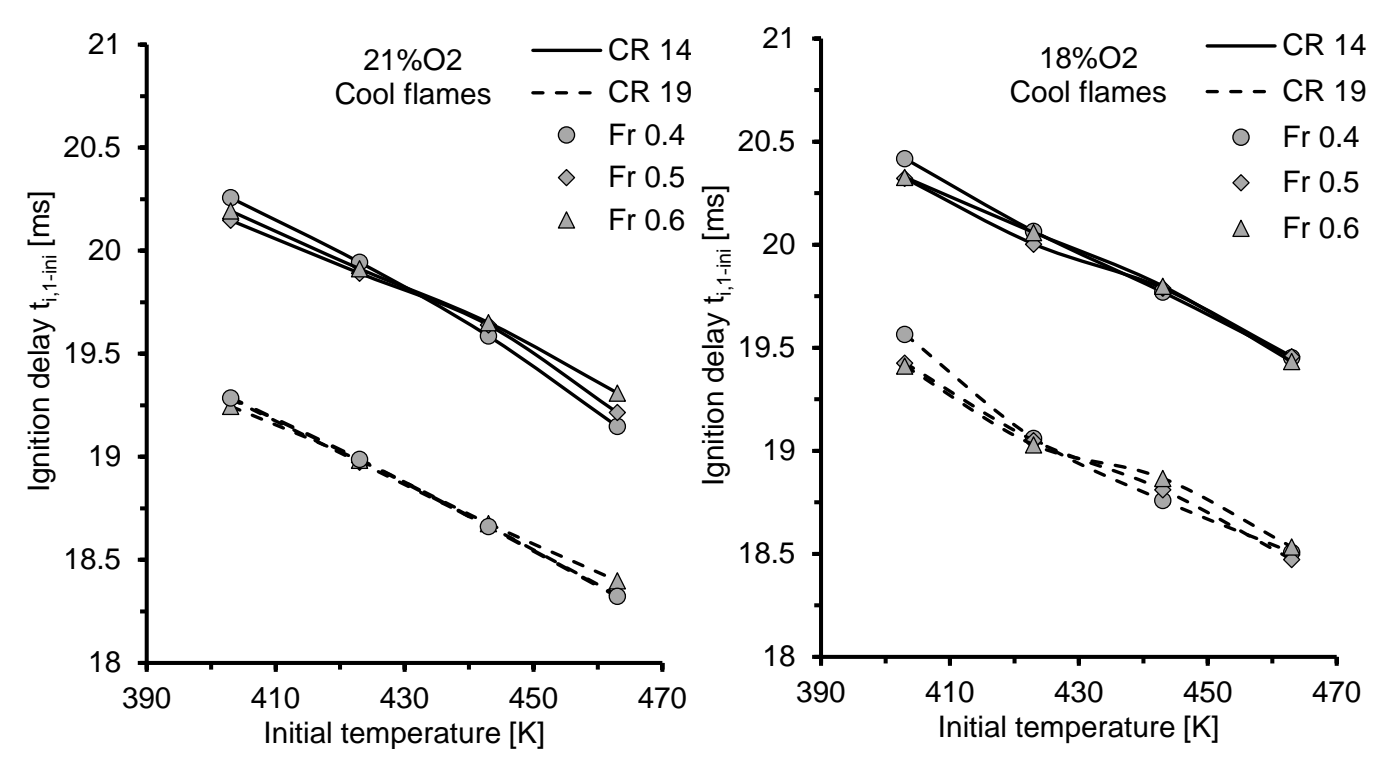

Figure C.15: Ignition delay, $t_{i, 1-i n i}$, versus initial temperature for different equivalence ratios. Both compression ratios are plotted. Left.- $\mathrm{X}_{O_{2}}=0.21$. Right.- $\mathrm{X}_{O_{2}}=0.18$.

is increased following an almost constant decreasing rate. Thus, the time at which cool flames occur does not present the typical behavior caused by an NTC zone. The first exothermic reactions promote the competition between radicals, i.e., the NTC behavior, which leads to a sudden decrease of the exothermic activity causing a previous peak of heat release that corresponds to cool flames. Therefore, $t_{i, 1-i n i}$ occurs before the loss of reactivity caused by the NTC behavior, which means that it is not affected by the NTC zone. Besides, the ignition delay referred to cool flames seems to be highly dependent on temperature. In fact, $t_{i, 1-i n i}$ decreases when the compression ratio is increased because of the higher temperatures reached during the compression stroke.

On the other hand, Fig. C.15 also shows that the ignition delay referred 
to cool flames is very insensitive to changes of equivalence ratio. This is caused because of two different effects. First, $t_{i, 1-i n i}$ decreases when the equivalence ratio is increased, since the chain reactions that promote cool flames depends directly on the amount of fuel (despite the fact that the dependency of $t_{i, 1-i n i}$ on the equivalence ratio is much lower than in case of $\left.t_{i, 2-i n i}[46]\right)$. Secondly, the higher the equivalence ratio, the lower the adiabatic coefficient of the mixture, leading to lower temperatures during the compression stroke and, therefore, to longer ignition delays referred to cool flames. This is the reason why for low initial temperatures $(403 \mathrm{~K})$ the longest ignition delay corresponds to the lowest equivalence ratio, while for high initial temperatures $(463 \mathrm{~K})$, where the differences in the adiabatic coefficient between mixtures are more dominant, the opposite behavior is seen. It should be noted that differences in the adiabatic coefficient associated to different equivalence ratios are not relevant enough to see any effect on the ignition delay referred to the high-temperature stage, as it can be seen in Fig. C.13.

Besides, Fig. C.14 to the left shows the dependence of the ignition delay, $t_{i, 1-i n i}$, on the oxygen content. The ignition delay referred to cool flames increases if the oxygen molar fraction is decreased, since the initiation reactions that cause the cool flames depends on the amount of oxygen. However, it can be seen that cool flames are less sensitive to changes of oxygen content than the ignition delay referred to the high-temperature stage, which is consistent with other results about the autoignition of n-alkanes that can be found in the literature [46].

A comparison between both ignition delay definitions (based on the ini- 


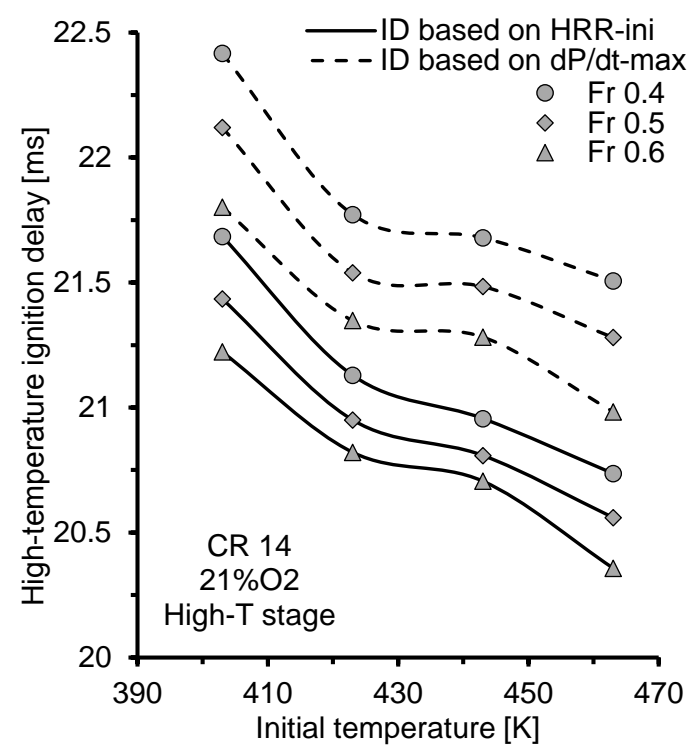

Figure C.16: High-temperature ignition delay versus initial temperature for $\mathrm{CR}=14, \mathrm{X}_{\mathrm{O}_{2}}$ $=0.21$ and different equivalence ratios. Both ignition delay definitions are plotted.

tial part of the HRR and based on the maximum of $d P / d t)$ can be seen in Fig. C.16. The experimental trends obtained by applying each definition are consistent with each other, existing a gap between data caused by the combustion velocity. This demonstrates that all the comments introduced above about the trends in $t_{i, n-i n i}$ can be also applied for $t_{i, n-\max }$.

Finally, a statistical analysis of the experimental measurements is shown in Tables C.9, C.10 and C.11, in which the experimental ignition delays based on the HRR criterion are included.

\section{References}

[1] T. Kamimoto and M. Bae. High combustion temperature for the reduction of particulate in diesel engines. SAE Technical Paper 880423, 


\begin{tabular}{|c|c|c|c|c|c|c|c|}
\hline $\mathbf{X}_{O_{2}}[-]$ & CR [-] & $\mathbf{T}_{i}[K]$ & $\operatorname{Fr}[-]$ & $\mathbf{t}_{i, 1}[m s]$ & $\mathbf{C V}[\%]$ & $\mathbf{t}_{i, 2}[m s]$ & $\mathbf{C V}[\%]$ \\
\hline \multirow{24}{*}{0.21} & \multirow{12}{*}{14} & \multirow{3}{*}{403} & 0.4 & 20.257 & 0.219 & 21.685 & 0.318 \\
\hline & & & 0.5 & 20.148 & 0.096 & 21.435 & 0.146 \\
\hline & & & 0.6 & 20.193 & 0.123 & 21.223 & 0.132 \\
\hline & & \multirow{3}{*}{423} & 0.4 & 19.944 & 0.350 & 21.129 & 0.413 \\
\hline & & & 0.5 & 19.891 & 0.272 & 20.951 & 0.306 \\
\hline & & & 0.6 & 19.913 & 0.156 & 20.821 & 0.380 \\
\hline & & \multirow{3}{*}{443} & 0.4 & 19.586 & 0.221 & 20.956 & 0.264 \\
\hline & & & 0.5 & 19.639 & 0.180 & 20.809 & 0.264 \\
\hline & & & 0.6 & 19.651 & 0.144 & 20.706 & 0.082 \\
\hline & & \multirow{3}{*}{463} & 0.4 & 19.148 & 0.244 & 20.736 & 0.359 \\
\hline & & & 0.5 & 19.215 & 0.173 & 20.560 & 0.269 \\
\hline & & & 0.6 & 19.310 & 0.213 & 20.224 & 0.265 \\
\hline & \multirow{12}{*}{19} & \multirow{3}{*}{403} & 0.4 & 19.287 & 0.118 & 20.485 & 0.192 \\
\hline & & & 0.5 & 19.282 & 0.156 & 20.380 & 0.214 \\
\hline & & & 0.6 & 19.246 & 0.161 & 20.193 & 0.188 \\
\hline & & \multirow{3}{*}{423} & 0.4 & 18.987 & 0.263 & 20.145 & 0.313 \\
\hline & & & 0.5 & 18.973 & 0.132 & 20.058 & 0.134 \\
\hline & & & 0.6 & 18.983 & 0.210 & 19.890 & 0.233 \\
\hline & & \multirow{3}{*}{443} & 0.4 & 18.662 & 0.219 & 19.923 & 0.123 \\
\hline & & & 0.5 & 18.664 & 0.206 & 19.761 & 0.416 \\
\hline & & & 0.6 & 18.677 & 0.204 & 19.636 & 0.225 \\
\hline & & \multirow{3}{*}{463} & 0.4 & 18.323 & 0.280 & 19.951 & 0.608 \\
\hline & & & 0.5 & 18.330 & 0.227 & 19.747 & 0.338 \\
\hline & & & 0.6 & 18.399 & 0.301 & 19.644 & 0.366 \\
\hline
\end{tabular}

Table C.9: Ignition delays referred to cool flames and referred to the high-temperature stage $\mathrm{X}_{\mathrm{O}_{2}}=0.21$. The coefficient of variation, $C V$, of each parameter is also shown. 


\begin{tabular}{|c|c|c|c|c|c|c|c|}
\hline $\mathbf{X}_{O_{2}}[-]$ & CR [-] & $\mathbf{T}_{i}[K]$ & $\operatorname{Fr}[-]$ & $\mathbf{t}_{i, 1}[\mathrm{~ms}]$ & $\mathbf{C V}[\%]$ & $\mathbf{t}_{i, 2}[\mathrm{~ms}]$ & $\mathbf{C V}[\%]$ \\
\hline \multirow{3}{*}{0.1839} & \multirow{12}{*}{14} & \multirow{3}{*}{403} & 0.4 & 20.418 & 0.467 & 22.117 & 0.371 \\
\hline & & & 0.5 & 20.322 & 0.171 & 21.801 & 0.410 \\
\hline & & & 0.6 & 20.328 & 0.422 & 21.640 & 0.471 \\
\hline \multirow{3}{*}{0.1846} & & \multirow{3}{*}{423} & 0.4 & 20.065 & 0.359 & 21.620 & 0.500 \\
\hline & & & 0.5 & 20.003 & 0.443 & 21.322 & 0.504 \\
\hline & & & 0.6 & 20.191 & 0.127 & 21.202 & 0.632 \\
\hline \multirow{3}{*}{0.1824} & & \multirow{3}{*}{443} & 0.4 & 19.508 & 0.375 & 20.880 & 0.559 \\
\hline & & & 0.5 & 19.558 & 0.160 & 20.696 & 0.256 \\
\hline & & & 0.6 & 19.599 & 0.135 & 20.608 & 0.130 \\
\hline \multirow{3}{*}{0.1829} & & \multirow{3}{*}{463} & 0.4 & 19.602 & 0.567 & 21.090 & 0.618 \\
\hline & & & 0.5 & 19.457 & 0.259 & 20.738 & 0.197 \\
\hline & & & 0.6 & 19.433 & 0.408 & 20.605 & 0.154 \\
\hline \multirow{3}{*}{0.1824} & \multirow{12}{*}{19} & \multirow{3}{*}{403} & 0.4 & 19.566 & 0.374 & 20.703 & 0.673 \\
\hline & & & 0.5 & 19.426 & 0.165 & 20.493 & 0.204 \\
\hline & & & 0.6 & 19.412 & 0.318 & 20.406 & 0.249 \\
\hline \multirow{3}{*}{0.1812} & & \multirow{3}{*}{423} & 0.4 & 19.060 & 0.229 & 20.336 & 0.250 \\
\hline & & & 0.5 & 19.050 & 0.314 & 20.090 & 0.377 \\
\hline & & & 0.6 & 19.029 & 0.192 & 19.998 & 0.200 \\
\hline \multirow{3}{*}{0.1846} & & \multirow{3}{*}{443} & 0.4 & 18.760 & 0.319 & 20.140 & 0.457 \\
\hline & & & 0.5 & 18.812 & 0.289 & 19.858 & 0.727 \\
\hline & & & 0.6 & 18.867 & 0.353 & 19.798 & 0.353 \\
\hline \multirow{3}{*}{0.1792} & & \multirow{3}{*}{463} & 0.4 & 18.508 & 0.337 & 19.948 & 0.277 \\
\hline & & & 0.5 & 18.473 & 0.207 & 19.656 & 0.205 \\
\hline & & & 0.6 & 18.534 & 0.111 & 19.556 & 0.184 \\
\hline
\end{tabular}

Table C.10: Ignition delays referred to cool flames and referred to the high-temperature stage $\mathrm{X}_{\mathrm{O}_{2}}=0.18$. The coefficient of variation, $C V$, of each parameter is also shown. 


\begin{tabular}{|c|c|c|c|c|c|c|c|}
\hline $\mathbf{X}_{O_{2}}[-]$ & CR [-] & $\mathbf{T}_{i}[K]$ & $\operatorname{Fr}[-]$ & $\mathbf{t}_{i, 1}[m s]$ & $\mathbf{C V}[\%]$ & $\mathbf{t}_{i, 2}[m s]$ & $\mathbf{C V}[\%]$ \\
\hline \multirow{3}{*}{0.1644} & \multirow{6}{*}{14} & \multirow{3}{*}{423} & 0.5 & 20.261 & 0.473 & 21.693 & 0.640 \\
\hline & & & 0.6 & 20.207 & 0.351 & 21.497 & 0.511 \\
\hline & & & 0.7 & 20.289 & 0.143 & 21.478 & 0.230 \\
\hline \multirow{3}{*}{0.1592} & & \multirow{3}{*}{463} & 0.5 & 19.377 & 0.251 & 20.904 & 0.268 \\
\hline & & & 0.6 & 19.379 & 0.351 & 20.683 & 0.482 \\
\hline & & & 0.7 & 19.485 & 0.289 & 20.664 & 0.320 \\
\hline \multirow{3}{*}{0.1616} & \multirow{6}{*}{19} & \multirow{3}{*}{423} & 0.5 & 19.212 & 0.262 & 20.477 & 0.137 \\
\hline & & & 0.6 & 19.165 & 0.233 & 20.292 & 0.197 \\
\hline & & & 0.7 & 19.139 & 0.096 & 20.185 & 0.129 \\
\hline \multirow{3}{*}{0.1591} & & \multirow{3}{*}{463} & 0.5 & 18.746 & 0.285 & 20.162 & 0.255 \\
\hline & & & 0.6 & 18.687 & 0.245 & 19.974 & 0.150 \\
\hline & & & 0.7 & 18.697 & 0.223 & 19.847 & 0.223 \\
\hline
\end{tabular}

Table C.11: Ignition delays referred to cool flames and referred to the high-temperature stage $\mathrm{X}_{O_{2}}=0.16$. The coefficient of variation, $C V$, of each parameter is also shown. 
1988.

[2] Y. Zhang and H. Zhao. Investigation of combustion, performance and emission characteristics of 2-stroke and 4-stroke spark ignition and CAI/HCCI operations in a DI gasoline. Applied Energy, 130:244-255, 2014.

[3] J.J. Lopez, R. Novella, J. Valero-Marco, G. Coma, and F. Justet. Evaluation of the potential benefits of an automotive, gasoline, 2-stroke engine. SAE Technical Paper, 2015-01-1261, 2015.

[4] John B. Heywood. Internal combustion engine fundamentals. McGrawHill series in mechanical engineering. McGraw-Hill, New York, 1988.

[5] T. Li, D. Wu, and M. Xu. Thermodynamic analysis of EGR effects on the first and second law efficiencies of a boosted spark-ignited directinjection gasoline engine. Energy Conversion and Management, 70:130138, 2013.

[6] K. Bahlouli, U. Atikol, R.K. Saray, and V. Mohammadi. A reduced mechanism for predicting the ignition timing of a fuel blend of naturalgas and n-heptane in HCCI engine. Energy Conversion and Management, 79:85-96, 2014.

[7] J. Benajes, J.V. Pastor, A. García, and J. Monsalve-Serrano. An experimental investigation on the influence of piston bowl geometry on RCCI performance and emissions in a heavy-duty engine. Energy Conversion and Management, 103:1019-1030, 2015. 
[8] P.W. Bessonette, C.H. Schleyer, K.P. Duffy, W.L. Hardy, and M.P. Liechty. Effects of fuel property changes on heavy-duty HCCI combustion. SAE Paper no. 200\%-01-0191, 2007.

[9] Z. Hu, B.L.M.T. Somers, R.F. Cracknell, and D. Bradley. Investigation of the livengood \& wu integral for modelling autoignition in a highpressure bomb. Combustion Theory and Modelling, 20:77-98, 2016.

[10] J.C. Livengood and P.C. Wu. Correlation of autoignition phenomena in internal combustion engines and rapid compression machines. Symposium (International) on Combustion, 5:347-356, 1955.

[11] L. Chen, T. Li, T. Yin, and B. Zheng. A predictive model for knock onset in spark-ignition engines with cooled EGR. Energy Conversion and Management, 87:946-955, 2014.

[12] M. Shahbakhti, R. Lupul, and C. R. Koch. Predicting HCCI autoignition timing by extending a modified knock-integral method. $S A E$ Paper no. 2007-01-0222, 2007.

[13] Y. Choi and J.Y. Chen. Fast prediction of start-of-combustion in HCCI with combined artificial neural networks and ignition delay model. Proceedings of the Combustion Institute, 30:2711-2718, 2005.

[14] D.J. Rausen, A.G. Stefanopoulou, J.M. Kang, J.A. Eng, and T.W. Kuo. A mean-value model for control of homogeneous charge compression ignition HCCI engines. Journal of Dynamic Systems, Measurement, and Control, 127:355-362, 2005. 
[15] Y. Ohyama. Engine control using a combustion model. Seoul 2000 FISITA World Automotive Congress, 2000.

[16] M. Hillion, J. Chauvin, and N. Petit. Control of highly diluted combustion in diesel engines. Control Engineering Practice, 19:1274-1286, 2011.

[17] A. Zhou, T. Dong, and B. Akih-Kumgeh. Simplifying ignition delay prediction for homogeneous charge compression ignition engine design and control. International Journal of Engine Research, 17:957-968, 2016.

[18] D. DelVescovo, S. Kokjohn, and R. Reitz. The development of an ignition delay correlation for prf fuel blends from prf0 (n-heptane) to prf100 (iso-octane). SAE Technical Paper 2016-01-0551, 2016.

[19] G. Amador, J. Duarte-Forero, A. Rincon, A. Fontalvo, A. Bula, R. Vasquez-Padilla, and W. Orozco. Characteristics of auto-ignition in internal combustion engines operated with gaseous fuels of variable methane number. Journal of Energy Resources Technology, 139, 2017.

[20] G. Kalghatgi, K. Morganti, I. Algunaibet, M. Sarathy, and R. Dibble. Knock prediction using a simple model for ignition delay. SAE Technical Paper 2016-01-0702, 2016.

[21] A.D.B. Yates, A. Swarts, and C.L. Viljoen. Correlating auto-ignition delays and knock-limited spark-advance data for different types of fuel. SAE Paper no. 2005-01-2083, 2005.

[22] J. M. Desantes, J. J. López, S. Molina, and D. López-Pintor. Validity of the Livengood \& Wu correlation and theoretical development of an 
alternative procedure to predict ignition delays under variable thermodynamic conditions. Energy Conversion and Management, 105:836-847, 2015.

[23] L. Liang and R.D. Reitz. Spark ignition engine combustion modeling using a level set method with detailed chemistry. SAE Paper no. 200601-0243, 2006.

[24] R. Edenhofer, K. Lucka, and H. Kohne. Low temperature oxidation of diesel-air mixtures at atmospheric pressure. Proceedings of the Combustion Institute, 31:2947-2954, 2007.

[25] J.J. Hernandez, M. Lapuerta, and J. Sanz-Argent. Autoignition prediction capability of the Livengood-Wu correlation applied to fuels of commercial interest. International Journal of Engine Research, 15:817$829,2014$.

[26] J. Pan, P. Zhao, C.K. La, and H. Wei. A predictive livengood?wu correlation for two-stage ignition. International Journal of Engine Research, $17: 825-835,2016$.

[27] J. M. Desantes, J. J. López, S. Molina, and D. López-Pintor. Validity of the Livengood \& $\mathrm{Wu}$ correlation and theoretical development of an alternative procedure to predict ignition delays under variable thermodynamic conditions. Energy Conversion and Management, 105:836-847, 2015 .

[28] J. M. Desantes, J. J. López, S. Molina, and D. López-Pintor. Theoretical development of a new procedure to predict ignition delays un- 
der transient thermodynamic conditions and validation using a Rapid Compression-Expansion Machine. Energy Conversion and Management, 108:132-143, 2016.

[29] I. Glassman and R.A. Yetter. Combustion. Elsevier Academic Press, 2008.

[30] J. M. Desantes, V. Bermúdez, J. J. López, and D. López-Pintor. A new method to predict high and low-temperature ignition delays under transient thermodynamic conditions and its experimental validation using a Rapid Compression-Expansion Machine. Energy Conversion and Management, 123:512-522, 2016.

[31] J. M. Desantes, V. Bermúdez, J. J. López, and D. López-Pintor. Experimental validation of an alternative method to predict high and lowtemperature ignition delays under transient thermodynamic conditions for PRF mixtures using a Rapid Compression-Expansion Machine. Energy Conversion and Management, 129:23-33, 2016.

[32] J. M. Desantes, J.M. García-Oliver, W. Vera-Tudela, D. López-Pintor, B. Schneider, and K. Boulouchos. Study of ignition delay time and generalization of auto-ignition for PRFs in a RCEM by means of natural chemiluminescence. Energy Conversion and Management, 111:217-228, 2016.

[33] J.M. Desantes, J.J. López, J.M. García-Oliver, and D. López-Pintor. A 5-zone model to improve the diagnosis capabilities of a Rapid 
Compression-Expansion Machine (RCEM) in autoignition studies. $S A E$ Paper no. 2017-01-0730, 2017.

[34] R. Payri, F.J. Salvador, J. Gimeno, and G. Bracho. A new methodology for correcting the signal cumulative phenomenon on injection rate measurements. Experimental Techniques, 32:46-49, 2008.

[35] J. M. Desantes, J. J. López, S. Molina, and D. López-Pintor. Design of synthetic EGR and simulation study of the effect of simplified formulations on the ignition delay of isooctane and n-heptane. Energy Conversion and Management, 96:521-531, 2015.

[36] G. Woschni. A universally applicable equation for the instantaneous heat transfer coefficient in the internal combustion engine. SAE Paper no. 670931, 1967.

[37] J. Benajes, P. Olmeda, J. Martín, and R. Carreño. A new methodology for uncertainties characterization in combustion diagnosis and thermodynamic modelling. Applied Thermal Engineering, 71:389-399, 2014.

[38] F. Payri, S. Molina, J. Martín, and O. Armas. Influence of measurement errors and estimated parameters on combustion diagnosis. Applied Thermal Engineering, 26:226-236, 2006.

[39] T. Lu, M. Plomer, Z. Luo, S.M. Sarathy, W.J. Pitz, S. Som, and D.E. Longman. Directed relation graph with expert knowledge for skeletal mechanism reduction. 7th US National Combustion Meeting, Paper 1A03,:203-248, 2011. 
[40] K. Narayanaswamy, P. Pepiot, and H. Pitsch. A chemical mechanism for low to high temperature oxidation of n-dodecane as a component of transportation fuel surrogates. Combustion and Flame, 161:866-884, 2014.

[41] Z. Luo, S. Som, S. M. Sarathy, M. Plomer, W. J. Pitz, D. E. Longman, and T. Lu. Development and validation of an n-dodecane skeletal mechanism for spray combustion applications. Combustion Theory and Modelling, 18:187-203, 2014.

[42] H. Wang, Y. Ra, M. Jia, and R.D. Reitz. Development of a reduced n-dodecane-pah mechanism and its application for n-dodecane soot predictions. Fuel, 136:25-36, 2014.

[43] T. Yao, Y. Pei, B.J. Zhong, S. Som, and T. Lu. A hybrid mechanism for n-dodecane combustion with optimized low-temperature chemistry. 9th US National Combustion Meeting, 2015.

[44] F. Payri, X. Margot, S. Patouna, F. Ravet, and M. Funk. Use of a single-zone thermodynamic model with detailed chemistry to study a natural gas fueled Homogeneous Charge Compression Ignition engine. Energy Conversion and Management, 53:298-304, 2012.

[45] S.M. Sarathy, C.K. Westbrook, M. Mehl, W.J. Pitz, C. Togbe, P. Dagaut, H. Wang, M.A. Oehlschlaeger, U. Niemann, K. Seshadri, P.S. Veloo, C. Ji, F.N. Egolfopoulos, and T. Lu. Comprehensive chemical kinetic modeling of the oxidation of 2-methylalkanes from c7 to c20. Combustion and Flame, 158:2338-2357, 2011. 
1046 [46] K. Kumar, G. Mittal, and C.J. Sung. Autoignition of n-decane un1047 der elevated pressure and low-to-intermediate temperature conditions. $1048 \quad$ Combustion and Flame, 156:1278-1288, 2009. 